\title{
Squaric Acid-Based Peptidic Inhibitors of Matrix Metalloprotease-1 (MMP-1)
}

\author{
M. Burak Onaran ${ }^{\dagger}$, Anthony B. Comeau ${ }^{\dagger}$, and Christopher T. Seto ${ }^{*}$ \\ Department of Chemistry, Brown University, Providence, RI 02912
}

\begin{abstract}
A series of squaric acid-peptide conjugates were synthesized and evaluated as inhibitors of MMP-1. The cyclobut-3-enedione core was substituted at the 3-position with several functional groups, such as $-\mathrm{N}($ alkyl $) \mathrm{OH},-\mathrm{NHOH}$ and $-\mathrm{OH}$, that are designed to bind to the zinc atom in the active site of the metalloprotease. The 4-position of the cyclobut-3-enedione was derivatized with mono- or dipeptides that are designed to bind in the $\mathrm{S1}^{\prime}$ and $\mathrm{S}^{\prime}$ ' subsites of the enzyme, and position the metal chelating group appropriately in the active site for binding to zinc. Positional scanning revealed that $-\mathrm{N}(\mathrm{Me})$ $\mathrm{OH}$ provided the highest level of inhibition among the chelating groups that were tested, and LeuTle-NHMe was the preferred amino acid sequence. A combination of these groups yielded an inhibitor with an $\mathrm{IC}_{50}$ value of $95 \mu \mathrm{M}$. For one inhibitor, conversion of one of the carbonyl groups on the cyclobut-3-enedione core to a thiocarbonyl group resulted in a 18-fold increase in potency, and yielded a compound with an $\mathrm{IC}_{50}$ value of $15 \mu \mathrm{M}$.
\end{abstract}

\section{Introduction}

\section{Matrix Metalloproteases (MMPs)}

Matrix metalloproteases are a family of structurally related endopeptidases that degrade and remodel components of the extracellular matrix (ECM). ${ }^{1}$ These enzymes regulate structure and sustain a balanced composition of the ECM, two processes that are important for maintaining normal physiology in a number of tissues. For example, MMPs play a crucial role in embryonic development, healing and reproduction.

The activity of MMPs is normally regulated at three levels: 1) gene transcription, 2) activation of MMP propeptides, and 3) inhibition of MMPs by tissue inhibitors of metalloproteases (TIMPs). ${ }^{2,3}$ Overexpression of MMPs and deregulation of their activity is associated with a variety pathological conditions including tumor growth and metastasis, ${ }^{4}$ angiogenesis, ${ }^{5}$ destruction of joints that causes osteoarthritis 6 and rheumatoid arthritis, ${ }^{7}$ periodontal disease ${ }^{8}$ and multiple sclerosis. ${ }^{9}$ Therefore, there is significant interest in developing MMP inhibitors for therapeutic applications.

\section{Biological Applications of Squaric Acids}

Squaric acid is a molecule that has significant aromatic character. In one resonance form it has two $\pi$ electrons and a negative charge on each of the carbonyl oxygen atoms (Figure 1). The conjugate base of squaric acid can serve as an electrostatic mimic of negatively charged groups that are common in biology including carboxylates and phosphate mono- and diesters. As a

Christopher_Seto@brown.edu.

${ }^{\dagger}$ These two authors contributed equally to this work. 
result, derivatives of squaric acid have been used as a replacement for these groups in a number of medicinal applications.

Our research group has used squaric acid derivatives to mimic the phosphate group in phosphotyrosine residues. We prepared a number of 3-hydroxy-4-aryl-cyclobut-3-enediones as non-hydrolyzable isosteres of aryl phosphate esters and found that these compounds are effective inhibitors of protein tyrosine phosphatases. ${ }^{10} \mathrm{Kim}$ and coworkers have used phosphonocyclobutenedione as a mimic of pyrophosphate and found that it is a selective inhibitor of DNA polymerases from several viruses. ${ }^{11}$ Sekine has used a diamide of squaric acid to replace a phosphate diester linkage in an oligodeoxynucleotide. ${ }^{12}$

Derivatives of squaric acid have also been used to mimic carboxylates by a number of investigators. Shinada replaced the $\gamma$-carboxylic acid of a glutamate residue within a polyamine toxin with a squaric acid derivative. The resulting compound was a selective agonist of ionotropic glutamate receptors. ${ }^{13}$ Sun and coworkers used a derivative of squaric acid in their investigations of an NMDA antagonist that regulates the activation of glutamate receptors.

${ }^{14}$ In this example, squaric acid mimics the natural glutamate agonist of the neuronal receptors. In its application as a guanidinium isotere, Butera used diaminocyclobutenedione as a replacement for the $N$-cyanoguanidine group in a bladder-selective potassium channel opener that is used as a treatment for urge urinary incontinence. ${ }^{15}$

Hydroxamic acids are potent inhibitors of zinc metalloproteases. X-ray crystal structures show that hydroxamic acids chelate to the active site zinc atom as shown in structure I (Figure 2).

16 In addition, Bruckner and coworkers have demonstrated that vinylogous hydroxamic acids that are derived from squaric acid are good metal chelators (see structure II in Figure 2). ${ }^{17}$ These two observations prompted us to investigate the potential of vinylogous hydroxamic acids that are based upon squaric acid as inhibitors of MMPs. We have derivatized the vinylogous hydroxamic acids with peptides in order to target them to the active site of the proteases.

\section{Results and Discussion \\ Synthesis of Compounds $4 a-4 f$}

We began our studies by making a series of simple derivatives to determine what functional group is preferred at the $\mathrm{R}^{1}$ position of the inhibitors (Scheme 1). Squaric acid $\mathbf{1}$ was converted to its dimethyl ester $\mathbf{2}$ by treating it with trimethyl orthoformate. Reaction of compound $\mathbf{2}$ with a series of hydroxylamines gave vinylogous hydroxamic acids $\mathbf{3 a}-\mathbf{e}$. Substitution of the remaining methyl ester with several primary amines gave inhibitors $\mathbf{4 a - f}$.

These compounds were screened for activity against MMP-1. Assays were performed in a buffer of $200 \mathrm{mM} \mathrm{NaCl}, 50 \mathrm{mM}$ Tris, $5 \mathrm{mM} \mathrm{CaCl}_{2}, 20 \mu \mathrm{M} \mathrm{ZnSO}_{4}, 0.05 \%$ Brij 35 at pH 7.6 using the fluorogenic substrate Dnp-Pro-Cha-Gly-Cys(Me)-His-Ala-Lys(Nma)-NH $\mathrm{NH}_{2}$. In this substrate, $N$-methylanthranilic acid (Nma) is a fluorophore and the dinitrophenyl (Dnp) group is a quencher. ${ }^{18,19}$ The progress of the reactions was monitored by fluorescence spectroscopy with excitation at $340 \mathrm{~nm}$ and emission at $460 \mathrm{~nm}$. For inhibitors $4 \mathbf{a}-\mathbf{b}, \mathrm{R}^{1}=\mathrm{H}$ while the $\mathrm{R}^{2}$ position was varied between a branched and a straight-chain alkyl group. Between these two compounds, inhibitor $\mathbf{4 b}$, which incorporates a simple n-hexyl chain, had the better activity. We next screened Me, cyclohexyl and benzyl groups at the $\mathrm{R}^{1}$ position, and found that large groups are unfavorable at this site. Compounds $\mathbf{4 e}$ and $\mathbf{4 f}$, where $\mathrm{R}^{1}$ is cyclohexyl or benzyl, were poor inhibitors that showed no activity up to $10 \mathrm{mM}$ concentration. Compound $\mathbf{4 c}$, which incorporates a smaller methyl group at the $\mathrm{R}^{1}$ position, was approximately three times more active than compound $\mathbf{4 b}$, where $\mathrm{R}^{1}=\mathrm{H}$. Both inhibitors $\mathbf{4} \mathbf{c}$ and $\mathbf{4 d}$ had $\mathrm{IC}_{50}$ values of 310 $\mu \mathrm{M}$. 


\section{Monopeptide Inhibitors}

We next turned our attention to inhibitors that incorporated a single amino acid in order to determine which amino acid side chain is preferred in the $\mathrm{S} 1^{\prime}$ subsite within the context of these inhibitors. As shown in Scheme 2, inhibitors 6a-g were synthesized by reaction of vinylogous hydroxamic acids $\mathbf{3 b}$ or $\mathbf{3 e}$ with a variety of amino acid methyl esters. We chose amino acids with hydrophobic side chains since data from the literature indicated that such structures are preferred in the $\mathrm{S} 1^{\prime}$ subsite. ${ }^{1}$

Comparison of inhibitors $6 \mathbf{a}$ and $\mathbf{6 b}$ shows that both methyl and isopropyl groups at the $\mathrm{R}^{1}$ position are small enough to be tolerated by the enzyme (Table 2). In addition, the enzyme appears to be fairly insensitive to the identity of the $\mathrm{R}^{3}$ side chain, since all of the inhibitors in this series gave $\mathrm{IC}_{50}$ values that range from 190 to $380 \mu \mathrm{M}$. Among these compounds inhibitor 6a had the best activity with an $\mathrm{IC}_{50}$ value of $190 \mu \mathrm{M}$.

\section{Dipeptide Inhibitors}

To improve the potency of the inhibitors, we extended their structure by incorporating a second amino acid that is designed to bind in the $\mathrm{S} 2$ ' subsite. X-ray crystallographic studies have shown that peptide-based hydroxamic acid inhibitors bind in the active site of MMPs by occupying the primed subsites. ${ }^{20}$ The synthesis of the inhibitors in this series is shown in Scheme 3. For these studies, we used the dibutyl ester of squaric acid $\mathbf{7}$ as the starting point. We found that this compound is more convenient to work with than the corresponding dimethyl ester, since the dibutyl ester has increased solubility in most common organic solvents.

Squaric acid was treated with tributyl orthoformate to give dibutyl ester 7. Subsequent reaction of 7 with $N$-methylhydroxylamine yielded compound $\mathbf{8}$. The dipeptide building blocks were prepared by coupling $N$-Boc amino acids $9 \mathbf{a}-\mathbf{g}$ with methylamine to give the corresponding $N$-methyl amides. These were treated with trifluoroacetic acid to give compounds $\mathbf{1 0 a}-\mathbf{g}$. Coupling of 10a-g with $N$-Boc-Ile or $N$-Boc-Leu, followed by Boc deprotection gave dipeptides 11a-h. Finally, reaction of the dipeptides with compound $\mathbf{8}$ in methanol at room temperature provided the desired inhibitors 12a-h.

Most of the inhibitors in this series incorporate the side chain of Ile at the $\mathrm{R}^{3}$ position because the data presented in Table 2 indicated that Ile is preferred in the $\mathrm{S} 1^{\prime}$ subsite. The side chains at the $\mathrm{R}^{4}$ position were chosen based upon literature precedent, which suggest that aromatic and hydrophobic amino acids are preferred at the S2' subsite. ${ }^{1}$ For inhibitors $\mathbf{1 2 a}-\mathbf{g}$, which incorporate an Ile side chain at $\mathrm{R}^{3}$, we did not observe any improvement in activity over the related monopeptide inhibitor $\mathbf{6 a}$. In addition, the activity did not depend strongly on the structure of $\mathrm{R}^{4}$, since we observe a difference in $\mathrm{IC}_{50}$ values of only 2.5 -fold among these seven compounds.

Compounds 12a and 12h provide an interesting comparison. Both incorporate at bulky t-butyl group at $\mathrm{R}^{4}$. Compound 12a incorporates the side chain of Ile at $\mathrm{R}^{3}$, and was the least active among 12a-g. By contrast, 12h has a Leu side chain at $R^{3}$ and it is $2-5$-fold more active than any of the other mono- or dipeptide-based inhibitors. These data suggest that binding interactions in the $\mathrm{S}^{\prime}$ and $\mathrm{S} 2^{\prime}$ subsites are dependent on one another. For the monopeptide inhibitors that leave the S2' subsite empty (Table 2, compare inhibitors $\mathbf{6 a}$ and $\mathbf{6 d}$ ), Ile is preferred over Leu at $\mathrm{S1}^{\prime}$. This selectivity is reversed in the dipeptide inhibitors. With Tle in the $\mathrm{S} 2^{\prime}$ subsite, Leu is preferred over Ile at S1' (compare 12a and 12h).

\section{Squaric Acid Monoamides}

We also made a cursory examination of a simple monoamide of squaric acid as a potential MMP-1 inhibitor. Scheme 4 shows the synthesis of compound $\mathbf{1 4}$, which is the squaric acid 
analog of the vinylogous hydroxamic acid inhibitor 12h. Reaction of H-Leu-Tle-NHMe (11h) with dimethyl squarate $\mathbf{2}$ gave compound $\mathbf{1 3}$, which was subsequently hydrolyzed under acidic conditions to give compound $\mathbf{1 4}$.

When compound 14 was assayed against MMP-1, we observed no inhibition up to a concentration of $200 \mu \mathrm{M}$. In retrospect, this result is not surprising since the bite angle between the two oxygen atoms in squaric acid is known to be too large to form a strong five-membered chelate with $\mathrm{Zn}^{+2}$ (right side of Figure 3). ${ }^{21}$ By comparison, the vinylogous hydroxamic acid inhibitors have the potential to form a six-membered chelate with zinc (left side of Figure 3). This structure has a reduced bite angle and a shorter distance between the two chelating oxygen atoms. Both of these factors favor binding to the metal center. ${ }^{22}$

\section{Thiocarbonyl- Vs. Carbonyl-Containing Inhibitors}

Despite the fact that hydroxamic acids are potent inhibitors of metalloproteases, they have met with limited success in the clinic because of unfavorable oral bioavailability, stability in vivo and side effects. ${ }^{23}$ As a result, investigators have been working to discover alternate zincbinding motifs as a substitute for hydroxamic acids. One such example has been published by Cohen and coworkers, who reported hydroxypyridinone and pyrone ligands as promising alternatives to hydroxamic acids. ${ }^{24}$ Among the compounds assayed, the zinc chelators that incorporated a thiocarbonyl group had lower $\mathrm{IC}_{50}$ values when compared to their non-sulfur containing analogues.

To apply this strategy to the squaric/hydroxamic acid hybrids, we first needed to develop a reliable method for incorporating sulfur into the inhibitors. Squaric acid monoester $\mathbf{3 b}$ (Scheme 2) did not react with a variety of thionating agents including $\mathrm{P}_{2} \mathrm{~S}_{5} /$ hexamethyldisiloxane and Lawesson's reagent. By contrast, the squaric acid monoamide $6 \mathbf{a}$ reacted with both $\mathrm{P}_{2} \mathrm{~S}_{5}$ and Lawesson's reagent to give a product that incorporated a single sulfur atom in place of oxygen, as determined by mass spectrometry. Since Lawesson's reagent provided the cleaner of the two reactions, this method was used to convert $6 \mathbf{a}, 12 \mathrm{~d}, \mathbf{1 2} \mathrm{g}$ and $\mathbf{1 2 h}$ into the corresponding thiocarbonyl compounds (Scheme 5).

\section{Determining the Position of Sulfur Incorporation}

The inhibitors in Scheme 5 contain three or four different carbonyl groups, any of which could be the site of reaction with Lawesson's reagent. In order to determine the specific site that sulfur was incorporated into the molecules, we prepared two model compounds to aid us with this analysis (Scheme 6). Dibutyl squarate 7 was treated with two equivalents of $\mathrm{NH}_{2}$-PheOMe to give compound 19. When compound 19 was treated with less than one equivalent of Lawesson's reagent, the reaction yielded compound $\mathbf{2 0}$ in which one carbonyl group on the cyclobutenedione core had been replaced by a thiocarbonyl as determined by mass spectrometry. Ester carbonyl groups do not react with Lawesson's reagent under the reaction conditions that we employed $\left(25^{\circ} \mathrm{C}\right)$. In a similar manner, compound $\mathbf{6 e}$ was converted to 21.

The ${ }^{1} \mathrm{H}$ NMR spectrum of compound 19 (Figure 4) has a resonance at 5.0 PPM that corresponds to the $\alpha$-protons of the two Phe residues $\left(\mathrm{H}^{\mathrm{a}}\right)$. When this compound is treated with Lawesson's reagent to give compound 20, one of the $\alpha$-protons remains at 5.0 PPM $\left(\mathrm{H}^{\mathrm{c}}\right)$ while the other is shifted to 6.1 PPM $\left(\mathrm{H}^{\mathrm{b}}\right.$ shown in red). $\mathrm{H}^{\mathrm{b}}$ shifts downfield since the neighboring nitrogen atom of this Phe residue is in conjugation with the thiocarbonyl group, which is a better electron acceptor than a standard carbonyl. In a similar manner, compound $\mathbf{6 e}$ has a resonance at 5.0 PPM that corresponds the Phe $\alpha$-proton $\left(\mathrm{H}^{\mathrm{d}}\right)$. When this compound is converted to the monothiocarbonyl adduct 21, this proton shifts downfield to 6.2 PPM ( $\mathrm{H}^{\mathrm{e}}$ shown in red). This observation, along with the fact that compound $\mathbf{3 b}$ (Scheme 2) that also incorporates a $-\mathrm{N}$ 
$(\mathrm{OH}) \mathrm{Me}$ group does not react with Lawesson's reagent, suggests that the carbonyl group opposite the Phe residue in 6e was the site of reaction with Lawesson's reagent. Since we observe a similar shift for the $\alpha$-proton of the amino acid that is attached directly to the cyclobutenedione ring in compounds $6 \mathbf{a}, 12 \mathrm{~d}, 12 \mathrm{~g}$ and $\mathbf{1 2 h}$, we infer that all of these compounds react with Lawesson's reagent on the opposite side of the ring from the peptide chain (see the Supporting Information for the spectra).

Additional evidence for the site of sulfur incorporation comes from the chemical shift of the $\mathrm{OH}$ proton of the vinylogous hydroxamic acid in compounds $\mathbf{6 e}$ and $\mathbf{2 1}$. This proton appears at $10.7 \mathrm{ppm}$ in compound $\mathbf{6 e}$, since it participates in a strong hydrogen bond with the neighboring carbonyl group on the cyclobutenedione ring. However, the analogous proton in compound 21 appears at $8.5-9.0 \mathrm{ppm}$. This change in chemical shift is partly due to the fact that the thiocarbonyl group is a weaker hydrogen bond acceptor than the carbonyl group.

\section{Effect of the Thiocarbonyl Group on Inhibition}

As shown in Table 4, two of the compounds show improved activity against MMP-1 on conversion to their thiocarbonyl analogs, while the activity of the other two remain unchanged. Compound $\mathbf{1 5}$ is 2-3 times more potent than $\mathbf{6 a}$, while the potency of $\mathbf{1 6}$ is increased by 18fold compared to $\mathbf{1 2 d}$. By contrast, compounds $\mathbf{1 2} \mathbf{g}$ and $\mathbf{h}$ have similar $\mathrm{IC}_{50}$ values when compared to their thiocarbonyl analogs $\mathbf{1 7}$ and 18. These results suggest that conversion of a carbonyl group on the cyclobutenedione core of the inhibitors to a thiocarbonyl can be an effective method for improving inhibition. However, this improvement is dependent on the specific structure of the inhibitor. One plausible explanation for the observation that the potencies of compounds $\mathbf{1 2} \mathbf{g}$ and $\mathbf{h}$ do not change upon thionation is that the improvement in chelation between the cyclobutene core and the active site zinc atom changes the position of the bound inhibitor in the active site. This geometry change could decrease binding interactions between the peptide portion of the inhibitors and the S1' and S2' subsites, and offset the improved binding to zinc. By contrast, conversion of compounds $6 \mathbf{a}$ and $12 \mathbf{d}$ to their thiocarbonyl analogs could lead to improved binding with the zinc atom, and also may reposition the inhibitor in the active site so that it makes more favorable interactions with the distal enzyme subsites.

\section{Conclusions}

We have investigated the potential of a hybrid between squaric and hydroxamic acids to serve as a metal binding motif for the design of metalloprotease inhibitors. While hydroxamic acids are commonly used as MMP inhibitors, to the best of our knowledge this report represents the first use of a squaric acid derivative as a warhead for the design of inhibitors of metalloproteases. The squaric/hydroxamic acid hybrids are generally not as potent as hydroxamic acid-based inhibitors, many of which have inhibition constants in the $\mathrm{nM}$ range. However, since hydroxamic acids have not met with much success in the clinic, these hybrids could serve as an alternate starting point for the design of inhibitors with perhaps improved pharmacological properties. The structure of the peptidic portion of the inhibitors helps target them to the active site of zinc proteases, rather than to other classes of enzymes for which squaric acid derivatives can serve as inhibitors.

Among the alkyl groups that we have examined at the $-\mathrm{N}(\mathrm{OH})$ alkyl position of the inhibitors, small substituents such as Me and $i$-Pr are well accommodated in the active site of MMP-1, while sterically demanding groups such as Bn and cyclohexyl are too large and lead to poor activity. Among the inhibitors that do not contain a sulfur atom, we found that the dipeptide Leu-Tle-NHMe provided the highest level of activity when attached to the cyclobutenedione core. 
We also developed a regioselective method for converting one of the carbonyl groups on the core into the corresponding thiocarbonyl compound. This reaction occurs specifically at the position on the opposite side of the cyclobutene ring from the peptide substituent. Thionation of the inhibitors leads to improved activity in some cases, but not in others. Compound 12d gave the largest increase in potency upon thionation. The 18 -fold improvement resulted in an inhibitor with an $\mathrm{IC}_{50}$ value of $15 \mu \mathrm{M}$ against MMP-1.

\section{Experimental Section}

Full characterization for compounds $\mathbf{3 b}, \mathbf{3 c}$ and $\mathbf{3 e}$ has been reported in the literature. ${ }^{17}$

\section{3-(Hydroxyamino)-4-methoxy-3-cyclobutene-1,2-dione (3a)}

3,4-Dimethoxy-3-cyclobutene-1,2-dione 1 (200 $\mathrm{mg}, 1.4 \mathrm{mmol}$ ) was added to $10 \mathrm{~mL}$ of $\mathrm{MeOH}$ and stirred until all of the solids had dissolved. To this mixture was added hydroxylamine hydrochloride (104 mg, $1.5 \mathrm{mmol}$ ), the reaction mixture was cooled to $0{ }^{\circ} \mathrm{C}$, and $\mathrm{KOH}(94.3$ $\mathrm{mg}, 1.7 \mathrm{mmol}$ ) dissolved in $5 \mathrm{~mL}$ of $\mathrm{MeOH}$ was added. At this point the reaction contained a white precipitate. The reaction was monitored by TLC and upon disappearance of the starting material the mixture was filtered and the solid that was collected was washed with cold $\mathrm{MeOH}$. The filtrate and washes were combined and solvent was evaporated. The crude material was purified by column chromatography $\left(1: 9 \mathrm{MeOH} / \mathrm{CH}_{2} \mathrm{Cl}_{2}\right)$ to give compound $\mathbf{3 a}$ as a yellow solid (0.093 g, $0.650 \mathrm{mmol}, 47 \%) .{ }^{1} \mathrm{H}$ NMR $\left(300 \mathrm{MHz}, \mathrm{CD}_{3} \mathrm{OD}\right) \delta 4.37(\mathrm{~s}, 3 \mathrm{H}) ;{ }^{13} \mathrm{C}$ NMR $\left(100 \mathrm{MHz}, \mathrm{CD}_{3} \mathrm{OD}\right) \delta 184.9,181.5,174.4,170.1,60.1$; HRMS-ESI $\left(\mathrm{M}+\mathrm{H}^{+}\right)$calcd for $\mathrm{C}_{5} \mathrm{H}_{6} \mathrm{NO}_{4}$ 144.0297, found 144.0292.

\section{3-[(Benzyl)hydroxyamino]-4-methoxy-3-cyclobutene-1,2-dione (3d)}

This compound was prepared using $N$-benzylhydroxylamine hydrochloride $(0.367 \mathrm{~g}, 2.3$ $\mathrm{mmol})$ and $\mathbf{1}(0.30 \mathrm{~g}, 2.1 \mathrm{mmol})$ according to the procedure described above for the preparation of compound 3a. Purification of 3d was performed by column chromatography $(5: 95 \mathrm{MeOH} /$ $\left.\mathrm{CH}_{2} \mathrm{Cl}_{2}\right)$ to obtain a white solid $(0.318 \mathrm{~g}, 1.37 \mathrm{mmol}, 65 \%) .{ }^{1} \mathrm{H} \mathrm{NMR}\left(300 \mathrm{MHz}, \mathrm{CD}_{3} \mathrm{OD}\right) \delta$ 7.39 (m, $5 \mathrm{H}), 4.88$ (s, $3 \mathrm{H}), 4.38$ (s, $3 \mathrm{H}) ;{ }^{13} \mathrm{C}$ NMR (75 MHz, CD $\left.{ }_{3} \mathrm{OD}\right) \delta$ 185.0, 181.3, 175.0, 169.0, 135.0, 129.0, 128.8, 128.5, 60.3, 57.3; HRMS-ESI $\left(\mathrm{M}+\mathrm{Na}^{+}\right)$calcd for $\mathrm{C}_{12} \mathrm{H}_{11} \mathrm{NO}_{4} \mathrm{Na}$ 256.0586, found 256.0590 .

\section{3-(Hydroxyamino)-4-[(2-methylpropyl)amino]-3-cyclobutene-1,2-dione (4a)}

To a solution of compound $3 \mathbf{a}(0.055 \mathrm{~g}, 0.383 \mathrm{mmol})$ dissolved in $\mathrm{MeOH}(1 \mathrm{~mL})$, isobutylamine $(0.062 \mathrm{~g}, 0.844 \mathrm{mmol})$ was added and the mixture was stirred at room temperature for $25 \mathrm{~h}$.

The solvent was evaporated and the product was purified by column chromatography (1:9:90 $30 \%$ aqueous $\left.\mathrm{NH}_{4} \mathrm{OH} / \mathrm{MeOH} / \mathrm{CH}_{2} \mathrm{Cl}_{2}\right)$ giving $4 \mathbf{a}(0.009 \mathrm{~g}, 0.049 \mathrm{mmol}, 13 \%)$ as a white solid. ${ }^{1} \mathrm{H}$ NMR (400 MHz, CD $\left.{ }_{3} \mathrm{OD}\right) \delta 3.39(\mathrm{~d}, J=6.8 \mathrm{~Hz}, 2 \mathrm{H}), 1.85(\mathrm{~m}, 1 \mathrm{H}), 0.96(\mathrm{~d}, J=5.2$ $\mathrm{Hz}, 6 \mathrm{H}) ;{ }^{13} \mathrm{C} \mathrm{NMR}\left(100 \mathrm{MHz}, \mathrm{CD}_{3} \mathrm{OD}\right) \delta 181.1,180.3,168.9,167.8,52.8,31.4,20.0$; HRMSESI $\left(\mathrm{M}+\mathrm{H}^{+}\right)$calcd for $\mathrm{C}_{8} \mathrm{H}_{12} \mathrm{~N}_{2} \mathrm{O}_{3}$ 185.0926, found 185.0932.

\section{3-(Hexylamino)-4-(hydroxyamino)-3-cyclobutene-1,2-dione (4b)}

Compound $\mathbf{3 b}(100 \mathrm{mg}, 0.70 \mathrm{mmol})$ was dissolved in $\mathrm{MeOH}(10 \mathrm{~mL})$ and hexylamine (84.9 $\mathrm{mg}, 0.84 \mathrm{mmol}$ ) was added to the solution. The reaction was stirred for $12 \mathrm{~h}$ at room temperature, after which time TLC showed that all the starting material was consumed. The solvent was then removed by rotary evaporation. The crude material was purified by column chromatography (1:9:90 30\% aqueous $\mathrm{NH}_{4} \mathrm{OH} / \mathrm{MeOH} / \mathrm{CH}_{2} \mathrm{Cl}_{2}$ ) to yield $\mathbf{4 b}$ as a yellow oil (17.8 mg, $0.084 \mathrm{mmol}, 12 \%) .{ }^{1} \mathrm{H}$ NMR (300 MHz, DMSO- $\left.d_{6}\right) \delta 3.35(\mathrm{~m}, 2 \mathrm{H}), 1.50(\mathrm{~m}, 2 \mathrm{H})$, $1.27(\mathrm{~m}, 6 \mathrm{H}), 0.86(\mathrm{~m}, 3 \mathrm{H}) ;{ }^{13} \mathrm{C}$ NMR $\left(75 \mathrm{MHz}, \mathrm{DMSO}-d_{6}\right) \delta 184.2,183.6,170.2,169.6$, 
44.1, 31.7, 31.6, 26.4, 23.0, 14.8; HRMS-ESI $\left(\mathrm{M}+\mathrm{H}^{+}\right)$calcd for $\mathrm{C}_{10} \mathrm{H}_{17} \mathrm{~N}_{2} \mathrm{O}_{3} 213.1239$, found 213.1250 .

\section{3-(Hexylamino)-4-(hydroxymethylamino)-3-cyclobutene-1,2-dione (4c)}

To a solution of $\mathbf{3 b}(0.157 \mathrm{~g}, 1.0 \mathrm{mmol})$ in $\mathrm{MeOH}(1 \mathrm{~mL})$, hexylamine $(0.111 \mathrm{~g}, 1.1 \mathrm{mmol})$ was added and the mixture was stirred at room temperature for $4 \mathrm{~h}$. The solvent was evaporated and the crude product was purified by column chromatography (1:9:90 30\% aqueous $\mathrm{NH}_{4} \mathrm{OH} /$ $\left.\mathrm{MeOH} / \mathrm{CH}_{2} \mathrm{Cl}_{2}\right)$ giving $4 \mathrm{c}(0.19 \mathrm{~g}, 0.84 \mathrm{mmol}, 84 \%)$ as a white solid. ${ }^{1} \mathrm{H}$ NMR $(400 \mathrm{MHz}$, $\left.\mathrm{CDCl}_{3}\right) \delta 11.19(\mathrm{~s}, 1 \mathrm{H}), 7.50(\mathrm{~s}, 1 \mathrm{H}), 3.59(\mathrm{~m}, 5 \mathrm{H}), 1.64(\mathrm{~m}, 2 \mathrm{H}), 1.32(\mathrm{~m}, 6 \mathrm{H}), 0.88(\mathrm{t}, J$ $=6.5 \mathrm{~Hz}, 3 \mathrm{H}) ;{ }^{13} \mathrm{C} \mathrm{NMR}\left(100 \mathrm{MHz}, \mathrm{CDCl}_{3}\right) \delta 178.9,177.5,166.8,164.9,45.0,41.4,31.4$, 30.9, 26.1, 22.6, 14.0; HRMS-FAB $\left(\mathrm{M}+\mathrm{Na}^{+}\right)$calcd for $\mathrm{C}_{11} \mathrm{H}_{18} \mathrm{~N}_{2} \mathrm{O}_{3} \mathrm{Na} 249.1215$, found 249.1220 .

\section{3-(Hydroxymethylamino)-4-(pentylamino)-3-cyclobutene-1,2-dione (4d)}

Compound 4d $(0.058 \mathrm{~g}, 0.27 \mathrm{mmol}, 37 \%)$ was prepared from $3 \mathbf{b}(0.118 \mathrm{~g}, 0.75 \mathrm{mmol})$ and pentylamine $(0.65 \mathrm{~g}, 0.75 \mathrm{mmol})$ according to the procedure used for preparing $4 \mathrm{c} .{ }^{1} \mathrm{H} \mathrm{NMR}$ $\left(400 \mathrm{MHz}, \mathrm{CDCl}_{3}\right) \delta 7.16(\mathrm{~s}, 1 \mathrm{H}), 3.56(\mathrm{~m}, 5 \mathrm{H}), 1.64(\mathrm{~m}, 2 \mathrm{H}), 1.33(\mathrm{~m}, 4 \mathrm{H}), 0.89(\mathrm{t}, J=6.8$ $\mathrm{Hz}, 3 \mathrm{H}) ;{ }^{13} \mathrm{C} \mathrm{NMR}\left(100 \mathrm{MHz}, \mathrm{CDCl}_{3}\right) \delta 178.9,177.4,166.7,165.1,45.0,41.4,30.7,28.6$, 22.3, 14.0; HRMS-FAB $\left(\mathrm{M}+\mathrm{Na}^{+}\right)$calcd for $\mathrm{C}_{10} \mathrm{H}_{16} \mathrm{~N}_{2} \mathrm{O}_{3} \mathrm{Na} 235.1059$, found 235.1066.

\section{3-[(Cyclohexyl)hydroxyamino]-4-(hexylamino)-3-cyclobutene-1,2-dione (4e)}

Compound $4 \mathbf{e}(0.0047 \mathrm{~g}, 0.016 \mathrm{mmol}, 13 \%)$ was prepared as a white solid from $3 \mathbf{c}(0.027 \mathrm{~g}$, $0.12 \mathrm{mmol})$ and hexylamine $(0.015 \mathrm{~g}, 0.144 \mathrm{mmol})$ according to the procedure used for preparation of 4b. ${ }^{1} \mathrm{H}$ NMR (400 MHz, DMSO- $\left.d_{6}\right) \delta 7.34$ (br s, $\left.2 \mathrm{H}\right), 3.76$ (br s, $\left.1 \mathrm{H}\right), 3.32$ (s, $4 \mathrm{H}), 3.52$ (s, $2 \mathrm{H}), 1.88$ (m, $2 \mathrm{H}), 1.70(\mathrm{~m}, 2 \mathrm{H}), 1.57$ (s, $3 \mathrm{H}), 1.27(\mathrm{~m}, 10 \mathrm{H}), 1.53(\mathrm{~m}, 3 \mathrm{H})$, $0.86(\mathrm{~m}, 3 \mathrm{H}) ;{ }^{13} \mathrm{C}$ NMR $\left(100 \mathrm{MHz}\right.$, DMSO- $\left.d_{6}\right) \delta 181.7,181.4,167.3,166.4,51.5,42.7,33.2$, 30.3, 30.2, 25.0, 24.3, 23.5, 21.5, 13.4; HRMS-ESI $\left(\mathrm{M}+\mathrm{H}^{+}\right)$calcd for $\mathrm{C}_{16} \mathrm{H}_{27} \mathrm{~N}_{2} \mathrm{O}_{3} 295.2022$, found 295.2018 .

\section{3-[(Benzyl)hydroxyamino]-4-(hexylamino)-3-cyclobutene-1,2-dione (4f)}

Compound $4 \mathbf{f}(0.232 \mathrm{~g}, 0.77 \mathrm{mmol}, 89 \%)$ was prepared as a white solid from $3 \mathbf{d}(0.200 \mathrm{~g}, 0.86$ $\mathrm{mmol})$ and hexylamine $(0.101 \mathrm{~g}, 1.00 \mathrm{mmol})$ according to the procedure used for the preparation of 4b. ${ }^{1} \mathrm{H}$ NMR $\left(300 \mathrm{MHz}, \mathrm{CD}_{3} \mathrm{OD}\right) \delta 7.36(\mathrm{~m}, 5 \mathrm{H}), 4.94(\mathrm{~s}, 2 \mathrm{H}), 3.58(\mathrm{t}, J=7.0$ $\mathrm{Hz}, 2 \mathrm{H}), 1.60(\mathrm{dd}, J=13.9,6.9 \mathrm{~Hz}, 2 \mathrm{H}), 1.34(\mathrm{~m}, 6 \mathrm{H}), 0.91(\mathrm{t}, J=6.7 \mathrm{~Hz}, 3 \mathrm{H}) ;{ }^{13} \mathrm{C} \mathrm{NMR}$ (75 MHz, CD 3 OD) $\delta 180.4,178.6,168.2$, 166.1, 135.6, 129.1 128.7, 128.3 57.5, 44.4, 31.6, 26.1, 22.7, 13.4; HRMS-ESI $\left(\mathrm{M}+\mathrm{H}^{+}\right)$303.1709, found 303.1711.

\section{3-(Hydroxymethylamino)-4-(L-isoleucine methyl ester)-3-cyclobutene-1,2-dione (6a)}

To a solution of $\mathbf{3 b}(0.219 \mathrm{~g}, 1.39 \mathrm{mmol})$ dissolved in $\mathrm{MeOH}(5 \mathrm{~mL})$, the hydrochloride salt of L-isoleucine methyl ester (5a) $(0.229 \mathrm{~g}, 1.26 \mathrm{mmol})$ was added. To this stirred solution $\mathrm{KOH}$ $(0.0713 \mathrm{~g}, 1.27 \mathrm{mmol})$ was added, and immediately a white precipitate formed. The reaction was stirred at room temperature for $12 \mathrm{~h}$ and solvent was evaporated. Purification was performed by column chromatography (1:9:90 30\% aqueous $\mathrm{NH}_{4} \mathrm{OH} / \mathrm{MeOH} / \mathrm{CH}_{2} \mathrm{Cl}_{2}$ ) to yield a yellowish flaky solid (0.238 g, $0.88 \mathrm{mmol}, 70 \%) .{ }^{1} \mathrm{H}$ NMR $\left(300 \mathrm{MHz}, \mathrm{CD}_{3} \mathrm{OD}\right) \delta 5.04$ (br s, $2 \mathrm{H}), 4.81$ (d, J = 7 Hz, $2 \mathrm{H}), 3.78(\mathrm{~s}, 3 \mathrm{H}), 3.50(\mathrm{~s}, 3 \mathrm{H}), 2.03(\mathrm{~m}, 1 \mathrm{H}), 1.54(\mathrm{~m}, 1 \mathrm{H}), 1.30$ $(\mathrm{m}, 1 \mathrm{H}), 0.97(\mathrm{~m}, 6 \mathrm{H}) ;{ }^{13} \mathrm{C}$ NMR $\left(75 \mathrm{MHz}, \mathrm{CD}_{3} \mathrm{OD}\right) \delta 180.4,180.0,173.0,167.6,167.0$, 62.4 52.8, 41.4, 39.4, 25.8, 15.6, 11.6; HRMS-ESI $\left(\mathrm{M}+\mathrm{H}^{+}\right)$calcd for $\mathrm{C}_{12} \mathrm{H}_{19} \mathrm{~N}_{2} \mathrm{O}_{5} 271.1294$, found 271.1287 . 
3-[Hydroxy(1-methylethyl)amino]-4-(L-isoleucine methyl ester)-3-cyclobutene-1,2-dione (6b)

Compound $\mathbf{6 b}(0.034 \mathrm{~g}, 0.11 \mathrm{mmol}, 26 \%)$ was prepared as a colorless solid starting from $3 \mathbf{e}$ $(0.080 \mathrm{~g}, 0.432 \mathrm{mmol})$ and $\mathbf{5 a}(0.120 \mathrm{~g}, 0.56 \mathrm{mmol})$ according to the procedure used for the preparation of $4 \mathbf{b} .{ }^{1} \mathrm{H}$ NMR $\left(300 \mathrm{MHz}, \mathrm{CD}_{3} \mathrm{OD}\right) \delta 7.28$ (br s, $\left.1 \mathrm{H}\right), 4.83$ (br s, $\left.1 \mathrm{H}\right), 4.52$ (br $\mathrm{s}, 1 \mathrm{H}), 3.73(\mathrm{~s}, 3 \mathrm{H}), 2.01(\mathrm{~s}, 1 \mathrm{H}), 1.49(\mathrm{~m}, 1 \mathrm{H}), 1.31(\mathrm{~m}, 7 \mathrm{H}), 0.93(\mathrm{~m}, 6 \mathrm{H}) ;{ }^{13} \mathrm{C}$ NMR $(75$ $\left.\mathrm{MHz}, \mathrm{CDCl}_{3}\right) \delta 179.1,179.0,172.0,166.7,165.5,61.8,55.5,52.7,38.7,25.1,19.8,15.5,11.8$; HRMS-ESI $\left(\mathrm{M}+\mathrm{H}^{+}\right)$calcd for $\mathrm{C}_{14} \mathrm{H}_{23} \mathrm{~N}_{2} \mathrm{O}_{5} 299.1607$, found 299.1602 .

\section{3-(Hydroxymethylamino)-4-(D,L-norleucine methyl ester)-3-cyclobutene-1,2-dione (6c)}

Compound $\mathbf{6 c}(0.09 \mathrm{~g}, 0.33 \mathrm{mmol}, 45 \%)$ was prepared from $\mathbf{3 b}(0.118 \mathrm{~g}, 0.75 \mathrm{mmol})$, D,Lnorleucine methyl ester $\mathrm{HCl}$ salt $(0.136 \mathrm{~g}, 0.75 \mathrm{mmol})$ and $\mathrm{KOH}(0.042 \mathrm{~g}, 0.75 \mathrm{mmol})$ according to the procedure used for preparing 6a. ${ }^{1} \mathrm{H}$ NMR $\left(400 \mathrm{MHz}, \mathrm{CDCl}_{3}\right) \delta 7.15(\mathrm{~d}, J=$ $8.4 \mathrm{~Hz}, 1 \mathrm{H}), 4.79(\mathrm{dt}, J=9.1,4.8 \mathrm{~Hz}, 1 \mathrm{H}), 3.73(\mathrm{~s}, 3 \mathrm{H}), 3.55(\mathrm{~s}, 3 \mathrm{H}), 1.95(\mathrm{~m}, 1 \mathrm{H}), 1.82$ $(\mathrm{m}, 1 \mathrm{H}), 1.36(\mathrm{~m}, 4 \mathrm{H}), 0.89(\mathrm{t}, J=7.1 \mathrm{~Hz}, 3 \mathrm{H}) ;{ }^{13} \mathrm{C} \mathrm{NMR}\left(100 \mathrm{MHz}, \mathrm{CDCl}_{3}\right) \delta 178.8,178.2$, 172.0, 165.9, 165.2, 57.0, 52.5, 41.3, 32.5, 27.6, 22.2, 13.8; HRMS-ESI $\left(\mathrm{M}+\mathrm{H}^{+}\right)$calcd for $\mathrm{C}_{12} \mathrm{H}_{19} \mathrm{~N}_{2} \mathrm{O}_{5} 271.1294$, found 271.1285.

\section{3-(Hydroxymethylamino)-4-(L-leucine methyl ester)-3-cyclobutene-1,2-dione (6d)}

Compound $\mathbf{6 d}$ was prepared as a white solid $(0.023 \mathrm{~g}, 0.076 \mathrm{mmol}, 38 \%)$ starting from $\mathbf{3 b}$ $(0.031 \mathrm{~g}, 0.20 \mathrm{mmol})$ and $\mathbf{5 c}(0.047 \mathrm{~g}, 0.26 \mathrm{mmol})$ according to the procedure used to prepare 6a. ${ }^{1} \mathrm{H}$ NMR ( $300 \mathrm{MHz}, \mathrm{CDCl}_{3}$ ) $\delta 7.14$ (br s, $\left.1 \mathrm{H}\right), 4.87$ (br s, $\left.1 \mathrm{H}\right), 3.72(\mathrm{~s}, 3 \mathrm{H}) 3.55(\mathrm{~s}, 3 \mathrm{H})$, $1.75(\mathrm{~m}, 1 \mathrm{H}), 0.96(\mathrm{~d}, J=4.8 \mathrm{~Hz}, 6 \mathrm{H}) ;{ }^{13} \mathrm{C} \mathrm{NMR}\left(100 \mathrm{MHz}, \mathrm{CD}_{3} \mathrm{OD}\right) \delta 184.5,183.5,174.1$, 170.3, 168.7, 54.8, 53.0, 31.3, 25.9, 23.4, 21.7; HRMS-ESI $\left(\mathrm{M}+\mathrm{Na}^{+}\right)$calcd for $\mathrm{C}_{12} \mathrm{H}_{18} \mathrm{~N}_{2} \mathrm{O}_{5} \mathrm{Na} 293.1113$, found 293.1118.

\section{3-(Hydroxymethylamino)-4-(L-phenylalanine methyl ester)-3-cyclobutene-1,2-dione (6e)}

Compound 6e (0.135 g, $0.44 \mathrm{mmol}, 59 \%)$ was prepared from $3 \mathbf{b}(0.118 \mathrm{~g}, 0.75 \mathrm{mmol})$, Lphenylalanine methyl ester $\mathrm{HCl}$ salt $(0.216 \mathrm{~g}, 1.0 \mathrm{mmol})$ and $\mathrm{KOH}(0.056 \mathrm{~g}, 1.0 \mathrm{mmol})$ according to the procedure used for preparing 6a. ${ }^{1} \mathrm{H}$ NMR $\left(400 \mathrm{MHz}, \mathrm{DMSO}-d_{6}\right) \delta 10.75(\mathrm{~s}$, $1 \mathrm{H}), 7.79(\mathrm{~s}, 1 \mathrm{H}), 7.25(\mathrm{~m}, 5 \mathrm{H}), 5.06(\mathrm{~s}, 1 \mathrm{H}), 3.70(\mathrm{~s}, 3 \mathrm{H}), 3.35$ (s, $3 \mathrm{H}), 3.28$ (dd, $J=14.0$, $3.9 \mathrm{~Hz}, 1 \mathrm{H}), 3.18(\mathrm{~m}, 1 \mathrm{H}) ;{ }^{13} \mathrm{C}$ NMR $\left(100 \mathrm{MHz}\right.$, DMSO- $\left.d_{6}\right) \delta 180.0,179.2,171.9,166.9$, 166.0, 137.7, 129.6, 128.8, 127.0, 57.6, 52.8, 41.2, 37.7; HRMS-FAB $\left(\mathrm{M}+\mathrm{Na}^{+}\right)$calcd for $\mathrm{C}_{15} \mathrm{H}_{16} \mathrm{~N}_{2} \mathrm{O}_{5} \mathrm{Na} 327.0957$, found 327.0948.

\section{3-(Hydroxymethylamino)-4-(L-tryptophan methyl ester)-3-cyclobutene-1,2-dione (6f)}

Compound $\mathbf{6 f}(0.16 \mathrm{~g}, 0.47 \mathrm{mmol}, 62 \%)$ was prepared from $3 \mathbf{b}(0.118 \mathrm{~g}, 0.75 \mathrm{mmol})$, Ltryptophan methyl ester $\mathrm{HCl}$ salt $(0.255 \mathrm{~g}, 1.0 \mathrm{mmol})$ and $\mathrm{KOH}(0.056 \mathrm{~g}, 1.0 \mathrm{mmol})$ according to the procedure used for preparing 6a. ${ }^{1} \mathrm{H}$ NMR $\left(300 \mathrm{MHz}, \mathrm{CD}_{3} \mathrm{OD}\right) \delta 7.56(\mathrm{~d}, J=7.7 \mathrm{~Hz}, 1$ H), $7.34(\mathrm{~d}, J=8.0 \mathrm{~Hz}, 1 \mathrm{H}), 7.07(\mathrm{~m}, 3 \mathrm{H}), 5.13(\mathrm{dd}, J=7.7,5.1 \mathrm{~Hz}, 1 \mathrm{H}), 3.76(\mathrm{~s}, 3 \mathrm{H}), 3.43$ $(\mathrm{m}, 5 \mathrm{H}) ;{ }^{13} \mathrm{C}$ NMR $\left(75 \mathrm{MHz}, \mathrm{CD}_{3} \mathrm{OD}\right) \delta 179.6,179.0,172.4,166.9,166.2,137.0,127.7$, 123.7, 121.5, 119.0, 118.2, 111.3, 109.1, 57.7, 52.1, 40.3, 28.7; HRMS-ESI $\left(\mathrm{M}+\mathrm{Na}^{+}\right)$calcd for $\mathrm{C}_{17} \mathrm{H}_{17} \mathrm{~N}_{3} \mathrm{O}_{5} \mathrm{Na} 366.1066$, found 366.1075 .

\section{3-(Hydroxymethylamino)-4-(L-methionine methyl ester)-3-cyclobutene-1,2-dione (6g)}

Compound $6 \mathrm{~g}(0.082 \mathrm{~g}, 0.28 \mathrm{mmol}, 38 \%)$ was prepared from $3 \mathbf{b}(0.118 \mathrm{~g}, 0.75 \mathrm{mmol})$, Lmethionine methyl ester $\mathrm{HCl}$ salt $(0.15 \mathrm{~g}, 0.75 \mathrm{mmol})$ and $\mathrm{KOH}(0.042 \mathrm{~g}, 0.75 \mathrm{mmol})$ according to the procedure used for preparing $6 \mathbf{6} .{ }^{1} \mathrm{H}$ NMR $\left(400 \mathrm{MHz}, \mathrm{CDCl}_{3}\right) \delta 7.30(\mathrm{~d}, J=7.8 \mathrm{~Hz}, 1$ H), 4.93 (dd, $J=12.7,8.5 \mathrm{~Hz}, 1 \mathrm{H}), 3.75(\mathrm{~s}, 3 \mathrm{H}), 3.55(\mathrm{~s}, 3 \mathrm{H}), 2.60(\mathrm{~m}, 2 \mathrm{H}), 2.27(\mathrm{~m}, 1 \mathrm{H})$, $2.17(\mathrm{td}, J=14.7,7.2 \mathrm{~Hz}, 1 \mathrm{H}), 2.10(\mathrm{~s}, 3 \mathrm{H}) ;{ }^{13} \mathrm{C} \mathrm{NMR}\left(100 \mathrm{MHz}, \mathrm{CDCl}_{3}\right) \delta 178.8,178.3$, 
171.6, 165.9, 165.3, 56.0, 52.8, 41.4, 31.8, 30.1, 15.4; HRMS-FAB $\left(\mathrm{M}+\mathrm{Na}^{+}\right)$calcd for $\mathrm{C}_{11} \mathrm{H}_{16} \mathrm{~N}_{2} \mathrm{O}_{5} \mathrm{SNa} 311.0678$, found 311.0685.

\section{3-Butoxy-4-(hydroxymethylamino)-3-cyclobutene-1,2-dione (8)}

To a stirred solution of HONHMe $\mathrm{HCl}$ salt $(2.631 \mathrm{~g}, 31.5 \mathrm{mmol})$ in $\mathrm{MeOH}(30 \mathrm{ml}), \mathrm{KOH}$ $(1.767 \mathrm{~g}, 31.5 \mathrm{mmol})$ and compound $7(4.766 \mathrm{~g}, 21.0 \mathrm{mmol})$ were added. The mixture was stirred overnight at room temperature, the solvent was evaporated, and the crude product was washed with $\mathrm{H}_{2} \mathrm{O}$, and then dissolved in EtOAc. The aqueous layer was extracted with EtOAc. The organic extracts were combined, dried over $\mathrm{MgSO}_{4}$, and the solvents were evaporated under reduced pressure. The crude product was purified by column chromatography (3\% $\mathrm{MeOH} / \mathrm{CH}_{2} \mathrm{Cl}_{2}$ ) to yield compound $\mathbf{8}$ as a pale yellow solid $(3.416 \mathrm{~g}, 17.2 \mathrm{mmol}, 82 \%) .{ }^{1} \mathrm{H}$ NMR (400 MHz, $\left.\mathrm{CDCl}_{3}\right) \delta 4.70(\mathrm{t}, J=6.6 \mathrm{~Hz}, 2 \mathrm{H}), 3.52(\mathrm{~s}, 3 \mathrm{H}), 1.77(\mathrm{~m}, 2 \mathrm{H}), 1.44(\mathrm{~m}, 2$ $\mathrm{H}), 0.97(\mathrm{t}, J=7.4 \mathrm{~Hz}, 3 \mathrm{H}) ;{ }^{13} \mathrm{C} \mathrm{NMR}\left(75 \mathrm{MHz}, \mathrm{CDCl}_{3}\right) \delta 184.0,180.7,174.3,169.1,74.2$, 41.6, 32.3, 18.9, 14.0; HRMS-FAB $\left(\mathrm{M}+\mathrm{Na}^{+}\right)$calcd for $\mathrm{C}_{9} \mathrm{H}_{13} \mathrm{NO}_{4} \mathrm{Na} 222.0742$, found 222.0740 .

\section{L-tert-Leucine methyl amide (10a)}

Compound 10a was synthesized starting from $N$-Boc- protected amino acid 9a. To a stirred solution of $N$-hydroxysuccinimide (NHS, $0.925 \mathrm{~g}, 8.04 \mathrm{mmol}$ ) in DMF $(20 \mathrm{~mL})$ under $\mathrm{N}_{2}$, $\mathrm{NH}_{2} \mathrm{Me}(4.02 \mathrm{~mL}, 2.0 \mathrm{M}$ in $\mathrm{MeOH}$ ) was added via syringe and the mixture was stirred for 30 $\mathrm{min}$ at room temperature. Formation of a white precipitate was observed. Addition of $\mathrm{N}$-Bocprotected amino acid $9 \mathrm{a}(1.55 \mathrm{~g}, 6.7 \mathrm{mmol})$ and cooling the mixture to $0{ }^{\circ} \mathrm{C}$ was followed by addition of 1-ethyl-3-(3-dimethylaminopropyl)-carbodiimide (EDC, $1.54 \mathrm{~g}, 8.04 \mathrm{mmol}$ ). The mixture was stirred for $1 \mathrm{~h}$ at $0{ }^{\circ} \mathrm{C}$ and $2 \mathrm{~h}$ at room temperature and then diluted with EtOAc. The solution was washed with $\mathrm{H}_{2} \mathrm{O}$, the organic layer was separated, and the aqueous layer was extracted with EtOAc. The combined organic extracts were washed with saturated $\mathrm{NaHCO}_{3}, \mathrm{H}_{2} \mathrm{O}$, and brine, dried over $\mathrm{MgSO}_{4}$, and the solvents were evaporated under reduced pressure. The crude product was purified by column chromatography $\left(3 \% \mathrm{MeOH} / \mathrm{CH}_{2} \mathrm{Cl}_{2}\right.$ ), washed with heptane, dried in vacuo and dissolved in $\mathrm{CH}_{2} \mathrm{Cl}_{2}(15 \mathrm{~mL})$. To this stirred solution, TFA ( $15 \mathrm{~mL})$ was added and the mixture was stirred for $40 \mathrm{~min}$ at room temperature. The solvents were removed in vacuo, and the residue was partitioned between $\mathrm{CH}_{2} \mathrm{Cl}_{2}(90 \mathrm{~mL})$ and saturated aqueous $\mathrm{NaHCO}_{3}(90 \mathrm{~mL})$. The organic phase was separated and the aqueous phase was extracted with $\mathrm{CH}_{2} \mathrm{Cl}_{2}$. The organic extracts were combined and dried over $\mathrm{Na}_{2} \mathrm{SO}_{4}$, and the solvents were evaporated. Purification was performed by column chromatography (5:95 $\mathrm{MeOH} / \mathrm{CH}_{2} \mathrm{Cl}_{2}$ ) yielding $10 \mathrm{a}$ as a colorless oil $(0.637 \mathrm{~g}, 4.42 \mathrm{mmol}, 66 \%) .{ }^{1} \mathrm{H} \mathrm{NMR}(300$ $\left.\mathrm{MHz}, \mathrm{CD}_{3} \mathrm{OD}\right) \delta 2.99(\mathrm{~s}, 1 \mathrm{H}), 2.75(\mathrm{~s}, 3 \mathrm{H}), 0.98(\mathrm{~s}, 9 \mathrm{H}) ;{ }^{13} \mathrm{C} \mathrm{NMR}\left(75 \mathrm{MHz}, \mathrm{CD}_{3} \mathrm{OD}\right) \delta$ 175.2, 63.9, 34.0, 25.9, 24.9; HRMS-FAB $\left(\mathrm{M}+\mathrm{Na}^{+}\right)$calcd for $\mathrm{C}_{7} \mathrm{H}_{16} \mathrm{~N}_{2} \mathrm{ONa} 167.1160$, found 167.1163.

\section{L-Cyclohexylglycine methyl amide (10b)}

Compound $10 \mathbf{b}$ was synthesized starting from $N$-Boc-protected amino acid $\mathbf{9 b}$. To a stirred solution of $N$-Boc-protected amino acid $9 \mathbf{b}(1.16 \mathrm{~g}, 4.52 \mathrm{mmol})$ in $\mathrm{CH}_{2} \mathrm{Cl}_{2}(20 \mathrm{~mL}), \mathrm{HOBt}$ (760 $\mathrm{mg}, 4.97 \mathrm{mmol})$ was added and then EDC $(911 \mathrm{mg}, 4.75 \mathrm{mmol})$ and mixture was stirred at $0{ }^{\circ} \mathrm{C}$ for $30 \mathrm{~min}$. Formation of a white precipitate was observed. To this solution $\mathrm{NH}_{2} \mathrm{Me}$ $(2.49 \mathrm{~mL}, 2.0 \mathrm{M}$ in $\mathrm{MeOH})$ was added via syringe and reaction was allowed to stir overnight. The solution was diluted with $\mathrm{CH}_{2} \mathrm{Cl}_{2}(50 \mathrm{~mL})$ and washed once with $1 \mathrm{M}$ citric acid $(30 \mathrm{~mL})$, once with saturated $\mathrm{NaHCO}_{3}(30 \mathrm{~mL})$ and then with brine $(30 \mathrm{~mL})$. The organic layer was then dried over $\mathrm{NaSO}_{4}$ and the solvent was evaporated under reduced pressure. The crude product was purified by column chromatography $\left(3 \% \mathrm{MeOH} / \mathrm{CH}_{2} \mathrm{Cl}_{2}\right)$ and the product was dissolved in $\mathrm{CH}_{2} \mathrm{Cl}_{2}(15 \mathrm{~mL})$. To this stirred solution TFA $(15 \mathrm{~mL})$ was added and the mixture was stirred at room temperature for $40 \mathrm{~min}$. The solvents were removed in vacuo, and the residue was 
partitioned between 1:1 $\mathrm{CH}_{2} \mathrm{Cl}_{2}$ /saturated aqueous $\mathrm{NaHCO}_{3}$. The organic phase was separated and the aqueous phase was extracted with $\mathrm{CH}_{2} \mathrm{Cl}_{2}$. The organic extracts were combined and dried over $\mathrm{Na}_{2} \mathrm{SO}_{4}$, and solvents were evaporated. Purification was performed by flash chromatography (5\% MeOH/ $\mathrm{CH}_{2} \mathrm{Cl}_{2}$ ) yielding $\mathbf{1 0 b}$ as a white solid $(440 \mathrm{mg}, 2.80 \mathrm{mmol}$, 62\%). ${ }^{1} \mathrm{H}$ NMR $\left(\mathrm{CDCl}_{3}, 300 \mathrm{MHz}\right) \delta 7.34($ br s, $1 \mathrm{H}), 3.22(\mathrm{~d}, J=3.8 \mathrm{~Hz}, 1 \mathrm{H}), 2.80(\mathrm{~d}, J=$ $5.0 \mathrm{~Hz}, 3 \mathrm{H}), 1.27(\mathrm{~m}, 14 \mathrm{H}) ;{ }^{13} \mathrm{C} \mathrm{NMR}\left(75 \mathrm{MHz}, \mathrm{CDCl}_{3}\right) \delta 175.5,60.5,41.5,30.6,27.0,26.7$, 26.6, 26.5, 26.0; HRMS-FAB $\left(\mathrm{M}+\mathrm{Na}^{+}\right)$calcd for $\mathrm{C}_{9} \mathrm{H}_{18} \mathrm{~N}_{2} \mathrm{NaO}$ 193.1317, found 193.1320.

\section{O-Methyl-L-tyrosine methyl amide (10c)}

The synthesis and the ${ }^{1} \mathrm{H}$ NMR spectrum for this compound have been reported previously. $25{ }^{13} \mathrm{C}$ NMR (75 MHz, CD ${ }_{3} \mathrm{OD}$ ) $\delta 175.9,158.6,129.9,129.3,113.5,56.5,54.2,40.3,24.7$; HRMS-ESI $\left(\mathrm{M}+\mathrm{Na}^{+}\right)$calcd for $\mathrm{C}_{11} \mathrm{H}_{16} \mathrm{~N}_{2} \mathrm{O}_{2} \mathrm{Na} 231.1109$, found 231.1115.

\section{L-Phenylalanine methyl amide (10d)}

Compound 10d (105 mg, $0.590 \mathrm{mmol}, 52 \%$ ) was prepared as a white solid from 9d (300 mg, $1.13 \mathrm{mmol}), \mathrm{HOBt}(190 \mathrm{mg}, 1.24 \mathrm{mmol}), \mathrm{EDC}(228 \mathrm{mg}, 1.19 \mathrm{mmol})$ and $\mathrm{NH}_{2} \mathrm{Me}(624 \mu \mathrm{L}$ of a $2.0 \mathrm{M}$ solution in $\mathrm{MeOH}$ ) according to the procedure used to prepare $10 \mathrm{~b} .{ }^{1} \mathrm{H}$ NMR (300 $\mathrm{MHz}, \mathrm{CDCl}_{3}$,) $\delta 7.26(\mathrm{~m}, 5 \mathrm{H}), 3.60(\mathrm{dd}, J=9.5,4.0 \mathrm{~Hz}, 1 \mathrm{H}), 3.28(\mathrm{dd}, J=13.7,4.0 \mathrm{~Hz}, 1$ $\mathrm{H}), 2.82(\mathrm{~d}, J=5 \mathrm{~Hz}, 3 \mathrm{H}), 2.67(\mathrm{dd}, J=13.7,9.5 \mathrm{~Hz}, 1 \mathrm{H}), 1.39(\mathrm{br} \mathrm{s}, 2 \mathrm{H}) ;{ }^{13} \mathrm{C}$ NMR $(75$ $\left.\mathrm{MHz}, \mathrm{CDCl}_{3}\right) \delta 174.8,138.0,129.3,128.7,126.8,56.5,41.0,25.8 ;$ HRMS-FAB $\left(\mathrm{M}+\mathrm{Na}^{+}\right)$ calcd for $\mathrm{C}_{10} \mathrm{H}_{14} \mathrm{~N}_{2} \mathrm{NaO} 201.1004$, found 201.1007.

\section{L-Phenylglycine methyl amide (10e)}

Compound 10e (0.836 g, $5.1 \mathrm{mmol}, 51 \%)$ was prepared from $6 \mathbf{e}(2.513 \mathrm{~g}, 10 \mathrm{mmol}), \mathrm{NH}_{2} \mathrm{Me}$ $(6.0 \mathrm{~mL}$ of a $2.0 \mathrm{M}$ solution in $\mathrm{MeOH})$, NHS (1.381 g, $12 \mathrm{mmol})$, EDC (2.3 g, $12 \mathrm{mmol})$ and TFA $(15 \mathrm{~mL})$ according to the procedure used for preparing 10a. The ${ }^{1} \mathrm{H}$ NMR and ${ }^{13} \mathrm{C}$ NMR spectra, and the HRMS for this compound have been reported previously. 26

\section{L-Tryptophan methyl amide (10f)}

The synthesis and the ${ }^{1} \mathrm{H}$ NMR spectrum for this compound have been reported previously. $24{ }^{13} \mathrm{C}$ NMR (75 MHz, CD 3 OD) $\delta$ 174.8, 135.3, 125.9, 121.8, 119.6, 116.9, 116.5, 109.4, 108.3, 54.0, 29.3, 23.3; HRMS-FAB $\left(\mathrm{M}+\mathrm{Na}^{+}\right)$calcd for $\mathrm{C}_{12} \mathrm{H}_{15} \mathrm{~N}_{3} \mathrm{ONa} 240.1113$, found 240.1117.

\section{L-Leucine methyl amide (10g)}

Compound $10 \mathrm{~g}(0.548 \mathrm{~g}, 3.8 \mathrm{mmol}, 42 \%)$ was prepared from $9 \mathrm{~g}(2.245 \mathrm{~g}, 9 \mathrm{mmol}), \mathrm{NH}_{2} \mathrm{Me}$ (5.4 mL of a $2.0 \mathrm{M}$ solution in MeOH), NHS (1.243 g, $10.8 \mathrm{mmol})$, EDC (2.068 g, $10.8 \mathrm{mmol})$ and TFA $(12 \mathrm{~mL})$ according to the procedure used for preparing 10a. ${ }^{1} \mathrm{H}$ NMR $(300 \mathrm{MHz}$, $\left.\mathrm{CD}_{3} \mathrm{OD}\right) \delta 3.33(\mathrm{dd}, J=7.7,6.5 \mathrm{~Hz}, 1 \mathrm{H}), 2.76(\mathrm{~s}, 3 \mathrm{H}), 1.68(\mathrm{qt}, J=12.9,6.5 \mathrm{~Hz}, 1 \mathrm{H}), 1.54$ (ddd, $J=13.8,7.4,6.4 \mathrm{~Hz}, 1 \mathrm{H}), 1.39(\mathrm{~m}, 1 \mathrm{H}), 0.95(\mathrm{t}, J=6.6 \mathrm{~Hz}, 6 \mathrm{H}) ;{ }^{13} \mathrm{C}$ NMR $(75 \mathrm{MHz}$, $\left.\mathrm{CD}_{3} \mathrm{OD}\right) \delta$ 177.0, 53.2, 44.2, 24.8, 24.5, 22.0, 21.1; HRMS-FAB $\left(\mathrm{M}+\mathrm{Na}^{+}\right)$calcd for $\mathrm{C}_{7} \mathrm{H}_{16} \mathrm{~N}_{2} \mathrm{ONa}$ 167.1160, found 167.1166.

\section{L-Isoleucyl-L-tert-leucine methyl amide (11a)}

To a stirred solution of NHS $(0.138 \mathrm{~g}, 1.2 \mathrm{mmol})$ in DMF $(5 \mathrm{~mL})$ under $\mathrm{N}_{2}, 10 \mathrm{a}(0.144 \mathrm{~g}, 1.0$ $\mathrm{mmol}$ ) was added and the mixture was stirred at room temperature for $30 \mathrm{~min}$. Addition of $\mathrm{N}$ Boc-L-isoleucine $(0.288 \mathrm{~g}, 1.2 \mathrm{mmol})$ and cooling the mixture to $0^{\circ} \mathrm{C}$ was followed by addition of $\operatorname{EDC}(0.23 \mathrm{~g}, 1.2 \mathrm{mmol})$. The mixture was stirred for $1 \mathrm{~h}$ at $0{ }^{\circ} \mathrm{C}$ and $2 \mathrm{~h}$ at room temperature and then diluted with EtOAc. The solution was washed with $\mathrm{H}_{2} \mathrm{O}$, the organic layer was separated, and the aqueous layer was extracted with EtOAc. The combined organic extracts 
were washed with saturated $\mathrm{NaHCO}_{3}, \mathrm{H}_{2} \mathrm{O}$, and brine, dried over $\mathrm{MgSO}_{4}$, and the solvents were evaporated under reduced pressure. The crude product was purified by column chromatography (3:97 MeOH/ $\mathrm{CH}_{2} \mathrm{Cl}_{2}$ ), washed with heptane, dried in vacuo and dissolved in $\mathrm{CH}_{2} \mathrm{Cl}_{2}(2 \mathrm{~mL})$. To this solution TFA $(2 \mathrm{~mL})$ was added and the mixture was stirred at room temperature for $40 \mathrm{~min}$. The solvents and TFA were removed, and the residue was partitioned between $\mathrm{CH}_{2} \mathrm{Cl}_{2}(15 \mathrm{~mL})$ and saturated aqueous $\mathrm{NaHCO}_{3}(15 \mathrm{~mL})$. Organic phase was separated and the aqueous phase was extracted with $\mathrm{CH}_{2} \mathrm{Cl}_{2}$. The organic extracts were combined and dried over $\mathrm{Na}_{2} \mathrm{SO}_{4}$, and the solvent was evaporated. Purification was performed by flash chromatography $\left(5: 95 \mathrm{MeOH} / \mathrm{CH}_{2} \mathrm{Cl}_{2}\right)$ yielding $11 \mathrm{a}$ as a colorless oil $(0.162 \mathrm{~g}, 0.63$ mmol, 63\%). ${ }^{1} \mathrm{H}$ NMR $\left(300 \mathrm{MHz}, \mathrm{CD}_{3} \mathrm{OD}\right) \delta 5.51(\mathrm{~s}, 1 \mathrm{H}), 4.19(\mathrm{~s}, 1 \mathrm{H}), 2.73(\mathrm{~s}, 3 \mathrm{H}), 1.79$ $(\mathrm{m}, 1 \mathrm{H}), 1.48(\mathrm{~m}, 1 \mathrm{H}), 1.16(\mathrm{~m}, 1 \mathrm{H}), 0.95(\mathrm{~m}, 15 \mathrm{H}) ;{ }^{13} \mathrm{C} \mathrm{NMR}\left(75 \mathrm{MHz}, \mathrm{CD}_{3} \mathrm{OD}\right) \delta 175.5$, 171.8, 60.6, 59.4, 38.6, 33.8, 25.7, 24.6, 23.8, 14.8, 10.7; HRMS-FAB $\left(\mathrm{M}+\mathrm{Na}^{+}\right)$calcd for $\mathrm{C}_{13} \mathrm{H}_{27} \mathrm{~N}_{3} \mathrm{O}_{2} \mathrm{Na} 280.2001$, found 280.2000.

\section{L-Isoleucyl-L-cyclohexylglycine methyl amide (11b)}

$N$-Boc-L-Isoleucine (140 mg, $0.584 \mathrm{mmol})$ was dissolved in $\mathrm{CH}_{2} \mathrm{Cl}_{2}(20 \mathrm{~mL})$ and the solution was cooled to $0{ }^{\circ} \mathrm{C}$. To this solution HOBt $(89.5 \mathrm{mg}, 0.584 \mathrm{mmol})$ and EDC (201 $\mathrm{mg}, 0.558$ $\mathrm{mmol}$ ) were added and the mixture was stirred for $30 \mathrm{~min}$. To this mixture compound $\mathbf{1 0 b}$ $(83.5 \mathrm{mg}, 0.531 \mathrm{mmol})$ was then added and reaction was stirred overnight. The solution was diluted with $\mathrm{CH}_{2} \mathrm{Cl}_{2}(50 \mathrm{~mL})$ and washed once with $1 \mathrm{M}$ citric acid $(30 \mathrm{~mL})$, once with saturated $\mathrm{NaHCO}_{3}(30 \mathrm{~mL})$ and then with brine $(30 \mathrm{~mL})$. The organic layer was dried over $\mathrm{NaSO}_{4}$ and the solvents evaporated under reduced pressure. The crude product was purified by column chromatography ( $3 \% \mathrm{MeOH} / \mathrm{CH}_{2} \mathrm{Cl}_{2}$ ) and then dissolved in $\mathrm{CH}_{2} \mathrm{Cl}_{2}(15 \mathrm{~mL})$. To this solution TFA $(15 \mathrm{~mL})$ was added and the mixture was stirred at room temperature for $40 \mathrm{~min}$. The solvents and TFA were evaporated, and the residue was partitioned between a 1:1 mixture of $\mathrm{CH}_{2} \mathrm{Cl}_{2}$ :saturated aqueous $\mathrm{NaHCO}_{3}$. The organic phase was separated and the aqueous phase was extracted with $\mathrm{CH}_{2} \mathrm{Cl}_{2}$. The organic extracts were combined and dried over $\mathrm{Na}_{2} \mathrm{SO}_{4}$, and the solvent was evaporated. Purification was performed by flash chromatography $(5 \% \mathrm{MeOH} /$ $\mathrm{CH}_{2} \mathrm{Cl}_{2}$ ) yielding 11b as a white solid (69 $\left.\mathrm{mg}, 0.244 \mathrm{mmol}, 46 \%\right) .{ }^{1} \mathrm{H} \mathrm{NMR}(400 \mathrm{MHz}$, $\left.\mathrm{CD}_{3} \mathrm{OD}\right) \delta 7.94(\mathrm{~d}, J=9.0 \mathrm{~Hz}, 1 \mathrm{H}), 6.98(\mathrm{~m}, 1 \mathrm{H}), 4.26(\mathrm{~m}, 1 \mathrm{H}), 3.28(\mathrm{~d}, J=4.0 \mathrm{~Hz}, 1 \mathrm{H})$, $2.78(\mathrm{~d}, J=4.8 \mathrm{~Hz}, 3 \mathrm{H}), 1.93(\mathrm{~m}, 1 \mathrm{H}), 1.75(\mathrm{~m}, 7 \mathrm{H}), 1.39(\mathrm{~m}, 2 \mathrm{H}), 1.25(\mathrm{~m}, 2 \mathrm{H}), 1.13(\mathrm{~m}$, $4 \mathrm{H}), 0.96(\mathrm{~d}, J=6.9 \mathrm{~Hz}, 3 \mathrm{H}), 0.90(\mathrm{t}, J=7.3 \mathrm{~Hz}, 3 \mathrm{H}) ;{ }^{13} \mathrm{C} \mathrm{NMR}\left(100 \mathrm{MHz}, \mathrm{CD}_{3} \mathrm{OD}\right) \delta$ 174.6, 171.9, 59.8, 57.8, 39.7, 38.1, 29.8, 28.8, 26.1, 25.9, 25.8, 25.8, 24.0, 16.1, 11.9 HRMSFAB $\left(\mathrm{M}+\mathrm{Na}^{+}\right)$calcd for $\mathrm{C}_{15} \mathrm{H}_{29} \mathrm{~N}_{3} \mathrm{NaO}_{2} 306.2157$, found 306.2150 .

\section{L-Isoleucyl-O-methyl-L-tyrosine methyl amide (11c)}

Compound 11c $(0.265 \mathrm{~g}, 0.82 \mathrm{mmol}, 58 \%)$ was prepared as a white solid from 10c $(0.295 \mathrm{~g}$, $1.42 \mathrm{mmol})$, NHS (0.196 g, $1.7 \mathrm{mmol}), N$-Boc-L-isoleucine ( $0.408 \mathrm{~g}, 1.7 \mathrm{mmol})$, EDC (0.326 $\mathrm{g}, 1.7 \mathrm{mmol})$ and TFA $(3 \mathrm{~mL})$ according to the procedure used for preparing 11a. ${ }^{1} \mathrm{H}$ NMR $\left(300 \mathrm{MHz}, \mathrm{CD}_{3} \mathrm{OD}\right) \delta 7.16(\mathrm{~d}, J=8.5 \mathrm{~Hz}, 2 \mathrm{H}), 6.84(\mathrm{~d}, J=8.5 \mathrm{~Hz}, 2 \mathrm{H}), 4.55(\mathrm{dd}, J=8.6$, $6.3 \mathrm{~Hz}, 1 \mathrm{H}), 3.76(\mathrm{~s}, 3 \mathrm{H}), 3.17(\mathrm{~d}, J=5.0 \mathrm{~Hz}, 1 \mathrm{H}), 3.07(\mathrm{dd}, J=13.8,6.2 \mathrm{~Hz}, 1 \mathrm{H}), 2.86$ (dd, $J=13.8,8.8 \mathrm{~Hz}, 1 \mathrm{H}), 2.69(\mathrm{~s}, 3 \mathrm{H}), 1.66(\mathrm{~m}, 1 \mathrm{H}), 1.18(\mathrm{~m}, 1 \mathrm{H}), 0.99(\mathrm{~m}, 1 \mathrm{H}), 0.83(\mathrm{~m}, 6$ $\mathrm{H}) ;{ }^{13} \mathrm{C}$ NMR $\left(75 \mathrm{MHz}, \mathrm{CD}_{3} \mathrm{OD}\right) \delta 175.6,172.7,158.7,129.9,128.8,113.5,59.6,54.7,54.2$, 38.5, 37.0, 24.9, 23.5, 14.7, 10.6; HRMS-FAB $\left(\mathrm{M}+\mathrm{Na}^{+}\right)$calcd for $\mathrm{C}_{17} \mathrm{H}_{27} \mathrm{~N}_{3} \mathrm{O}_{3} \mathrm{Na} 344.1950$, found 344.1942 .

\section{L-Isoleucyl-L-phenylalanine methyl amide (11d)}

Compound 11d (373 mg, $1.28 \mathrm{mmol}, 61 \%$ ) was prepared as a white solid from 10d (374 mg, $2.1 \mathrm{mmol}$ ), $\mathrm{HOBt}(322 \mathrm{mg}, 2.1 \mathrm{mmol}$ ), EDC (383 mg, $2.0 \mathrm{mmol}$ ) and $N$-Boc-L-Isoleucine (456 $\mathrm{mg}, 1.9 \mathrm{mmol}$ ) according to the procedure that was used to prepare 11b. ${ }^{1} \mathrm{H}$ NMR $(400 \mathrm{MHz}$, $\left.\mathrm{CDCl}_{3}\right) \delta 8.04(\mathrm{~d}, J=8.8 \mathrm{~Hz}, 1 \mathrm{H}), 7.18(\mathrm{~m}, 5 \mathrm{H}), 4.78(\mathrm{dt}, J=8.7,6.3 \mathrm{~Hz}, 1 \mathrm{H}), 2.98(\mathrm{dd}, J$ 
$=13.8,8.8 \mathrm{~Hz}, 1 \mathrm{H}), 2.68(\mathrm{~d}, J=4.8 \mathrm{~Hz}, 3 \mathrm{H}), 1.77(\mathrm{~m}, 1 \mathrm{H}), 0.99(\mathrm{~m}, 1 \mathrm{H}), 0.88(\mathrm{~m}, 1 \mathrm{H})$, $0.81(\mathrm{~d}, J=7.0 \mathrm{~Hz}, 3 \mathrm{H}), 0.75(\mathrm{t}, J=7.3 \mathrm{~Hz}, 3 \mathrm{H}) ;{ }^{13} \mathrm{C} \mathrm{NMR}\left(100 \mathrm{MHz}, \mathrm{CDCl}_{3}\right) \delta 175.0$, $171.9,137.1,129.2,128.4,126.7,59.8,54.0,38.4,26.0,23.4,15.9,11.8$; HRMS-FAB (M + $\mathrm{Na}^{+}$) calcd for $\mathrm{C}_{16} \mathrm{H}_{25} \mathrm{~N}_{3} \mathrm{NaO}_{2} 314.1844$, found 314.1850.

\section{L-Isoleucyl-L-phenylglycine methyl amide (11e)}

Compound 11e (0.032 g, $0.115 \mathrm{mmol}, 53 \%)$ was prepared from 10e $(0.036 \mathrm{~g}, 0.217 \mathrm{mmol})$, NHS $(0.03 \mathrm{~g}, 0.26 \mathrm{mmol}), N$-Boc-L-isoleucine $(0.062 \mathrm{~g}, 0.26 \mathrm{mmol}), \mathrm{EDC}(0.05 \mathrm{~g}, 0.26 \mathrm{mmol})$ and TFA $(0.35 \mathrm{~mL})$ according to the procedure used for preparing 11a. ${ }^{1} \mathrm{H}$ NMR $(400 \mathrm{MHz}$, $\left.\mathrm{CD}_{3} \mathrm{OD}\right) \delta 7.44(\mathrm{~m}, 2 \mathrm{H}), 7.34(\mathrm{~m}, 3 \mathrm{H}), 5.42(\mathrm{~s}, 1 \mathrm{H}), 3.29(\mathrm{~d}, J=5.3 \mathrm{~Hz}, 1 \mathrm{H}), 2.74(\mathrm{~s}, 3 \mathrm{H})$, $1.77(\mathrm{~m}, 1 \mathrm{H}), 1.47(\mathrm{~m}, 1 \mathrm{H}), 1.15(\mathrm{~m}, 1 \mathrm{H}), 0.96(\mathrm{~d}, J=6.9 \mathrm{~Hz}, 3 \mathrm{H}), 0.89$ (t, $J=7.4 \mathrm{~Hz}, 3$ $\mathrm{H}) ;{ }^{13} \mathrm{C}$ NMR $\left(100 \mathrm{MHz}, \mathrm{CD}_{3} \mathrm{OD}\right) \delta 175.1,171.4,137.7,128.3,127.9,127.1,59.2,57.0,38.8$, 25.0, 23.9, 14.6, 10.6; HRMS-FAB $\left(\mathrm{M}+\mathrm{Na}^{+}\right)$calcd for $\mathrm{C}_{15} \mathrm{H}_{23} \mathrm{~N}_{3} \mathrm{O}_{2} \mathrm{Na} 300.1688$, found 300.1680 .

\section{L-Isoleucyl-L-tryptophan methyl amide (11f)}

Compound $11 \mathrm{f}(0.103 \mathrm{~g}, 0.313 \mathrm{mmol}, 55 \%)$ was prepared from $10 f(0.124 \mathrm{~g}, 0.573 \mathrm{mmol})$, NHS (0.079 g, $0.688 \mathrm{mmol}), N$-Boc-L-isoleucine $(0.165 \mathrm{~g}, 0.688 \mathrm{mmol}), \mathrm{EDC}(0.132 \mathrm{~g}, 0.688$ $\mathrm{mmol})$ and TFA $(1 \mathrm{~mL})$ according to the procedure used to prepare 11a. ${ }^{1} \mathrm{H} \mathrm{NMR}(300 \mathrm{MHz}$, $\left.\mathrm{CD}_{3} \mathrm{OD}\right) \delta 7.57(\mathrm{~d}, J=7.8 \mathrm{~Hz}, 1 \mathrm{H}), 7.29(\mathrm{dd}, J=8.1,0.9 \mathrm{~Hz}, 1 \mathrm{H}), 7.02(\mathrm{~m}, 3 \mathrm{H}), 4.59(\mathrm{t}, J$ $=6.5,1 \mathrm{H}), 3.2(\mathrm{~d}, J=6.5,1 \mathrm{H}), 2.62(\mathrm{~d}, J=1.9,3 \mathrm{H}), 1.60(\mathrm{~m}, 1 \mathrm{H}), 1.14(\mathrm{~m}, 1 \mathrm{H}), 0.9(\mathrm{~m}$, $1 \mathrm{H}), 0.75(\mathrm{~m}, 6 \mathrm{H}) ;{ }^{13} \mathrm{C}$ NMR $\left(75 \mathrm{MHz}, \mathrm{CD}_{3} \mathrm{OD}\right) \delta 174.3,172.1,135.6,126.2,122.1,119.9$, 117.2, 116.8, 109.7, 108.3, 58.3, 52.9, 37.2, 26.7, 23.8, 22.3, 13.4, 9.4; HRMS-ESI $\left(\mathrm{M}+\mathrm{H}^{+}\right)$ calcd for $\mathrm{C}_{18} \mathrm{H}_{27} \mathrm{~N}_{4} \mathrm{O}_{2} 331.2134$, found 331.2138.

\section{L-Isoleucyl-L-leucine methyl amide (11g)}

Compound $11 \mathrm{~g}(0.219 \mathrm{~g}, 0.851 \mathrm{mmol}, 43 \%)$ was prepared from $10 \mathrm{~g}(0.285 \mathrm{~g}, 1.98 \mathrm{mmol})$, NHS (0.273 g, $2.375 \mathrm{mmol}), N$-Boc-L-isoleucine $(0.57 \mathrm{~g}, 2.375 \mathrm{mmol})$, EDC (0.455 g, 2.375 mmol) and TFA $(2.5 \mathrm{~mL})$ according to the procedure used to prepare 11a. ${ }^{1} \mathrm{H} \mathrm{NMR}(300 \mathrm{MHz}$, $\left.\mathrm{CD}_{3} \mathrm{OD}\right) \delta 4.4(\mathrm{t}, J=7.5,1 \mathrm{H}), 3.23(\mathrm{~d}, J=5.5,1 \mathrm{H}), 2.73(\mathrm{~s}, 3 \mathrm{H}), 1.61(\mathrm{~m}, 5 \mathrm{H}), 1.18(\mathrm{~m}, 1$ $\mathrm{H}), 0.94(\mathrm{~m}, 12 \mathrm{H}) ;{ }^{13} \mathrm{C}$ NMR $\left(75 \mathrm{MHz}, \mathrm{CD}_{3} \mathrm{OD}\right) \delta 175.9,174.2,59.9,51.9,41.2,39.3,25.4$, 24.9, 24.4, 22.5, 21.1, 15.1, 11.0; HRMS-FAB $\left(\mathrm{M}+\mathrm{Na}^{+}\right)$calcd for $\mathrm{C}_{13} \mathrm{H}_{27} \mathrm{~N}_{3} \mathrm{O}_{2} \mathrm{Na} 280.2001$, found 280.2006 .

\section{L-Leucyl-L-tert-leucine methyl amide (11h)}

Compound 11h $(0.054 \mathrm{~g}, 0.208 \mathrm{mmol}, 65 \%)$ was prepared from $10 \mathrm{~h}(0.046 \mathrm{~g}, 0.322 \mathrm{mmol})$, NHS (0.045 g, $0.386 \mathrm{mmol}), N$-Boc-L-leucine (0.096 g, $0.386 \mathrm{mmol})$, EDC (0.074 g, 0.386 $\mathrm{mmol})$ and TFA $(0.75 \mathrm{~mL})$ according to the procedure that was used to prepare 11a. ${ }^{1} \mathrm{H}$ NMR $\left(400 \mathrm{MHz}, \mathrm{CD}_{3} \mathrm{OD}\right) \delta 4.22(\mathrm{~s}, 1 \mathrm{H}), 3.46(\mathrm{t}, J=5.3,1 \mathrm{H}), 2.74(\mathrm{~s}, 3 \mathrm{H}), 1.76(\mathrm{~m}, 1 \mathrm{H}), 1.57$ $(\mathrm{m}, 1 \mathrm{H}), 1.41(\mathrm{~m}, 1 \mathrm{H}), 1.01(\mathrm{~m}, 9 \mathrm{H}), 0.97(\mathrm{~m}, 6 \mathrm{H}) ;{ }^{13} \mathrm{C} \mathrm{NMR}\left(100 \mathrm{MHz}, \mathrm{CD}_{3} \mathrm{OD}\right) \delta 176.8$, 172.1, 60.8, 53.6, 44.5, 34.5, 26.2, 25.1, 24.9, 22.7, 21.2; HRMS-FAB $\left(\mathrm{M}+\mathrm{Na}^{+}\right)$calcd for $\mathrm{C}_{13} \mathrm{H}_{27} \mathrm{~N}_{3} \mathrm{O}_{2} \mathrm{Na} 280.2001$, found 280.2010.

\section{General Procedure for the Synthesis of Compounds 12a-h}

To a stirred solution of $\mathbf{8}(1.0 \mathrm{eq})$ dissolved in $\mathrm{MeOH}, \mathbf{1 1} \mathbf{a}-\mathbf{h}(1.0 \mathrm{eq})$ was added and the mixture was stirred at room temperature overnight. The solvent was evaporated and the product was purified by column chromatography $\left(3: 97 \mathrm{MeOH} / \mathrm{CH}_{2} \mathrm{Cl}_{2}\right)$. 


\section{3-(Hydroxymethylamino)-4-(L-isoleucyl-L-tert-leucine methyl amide)-3-cyclobutene-1,2- dione (12a)}

Compound 12a $(0.03 \mathrm{~g}, 0.077 \mathrm{mmol}, 71 \%)$ was prepared from $8(0.022 \mathrm{~g}, 0.109 \mathrm{mmol})$ and $11 \mathrm{a}(0.028 \mathrm{~g}, 0.109 \mathrm{mmol})$ according to the general procedure. ${ }^{1} \mathrm{H} \mathrm{NMR}\left(300 \mathrm{MHz}, \mathrm{CD}_{3} \mathrm{OD}\right)$ $\delta 4.58(\mathrm{~d}, J=8.7 \mathrm{~Hz}, 1 \mathrm{H}), 4.23(\mathrm{~s}, 1 \mathrm{H}), 3.49(\mathrm{~s}, 3 \mathrm{H}), 2.73(\mathrm{~s}, 3 \mathrm{H}), 1.93(\mathrm{~m}, 1 \mathrm{H}), 1.62(\mathrm{~m}$, $1 \mathrm{H}), 1.23(\mathrm{~m}, 1 \mathrm{H}), 0.99(\mathrm{~s}, 9 \mathrm{H}), 0.94(\mathrm{~m}, 6 \mathrm{H}) ;{ }^{13} \mathrm{C} \mathrm{NMR}\left(75 \mathrm{MHz}, \mathrm{CD}_{3} \mathrm{OD}\right) \delta 179.5,178.9$, 172.0, 171.8, 166.5, 166.3, 62.4, 61.3, 40.2, 37.7, 34.2, 26.1, 24.9, 24.4, 14.5, 10.0; HRMSESI $\left(\mathrm{M}+\mathrm{Na}^{+}\right)$calcd for $\mathrm{C}_{18} \mathrm{H}_{30} \mathrm{~N}_{4} \mathrm{O}_{5} \mathrm{Na} 405.2114$, found 405.2126.

\section{3-(Hydroxymethylamino)-4-(L-isoleucyl-L-cyclohexylglycine methyl amide)-3- cyclobutene-1,2-dione (12b)}

Compound 12b (0.0106 g, $0.026 \mathrm{mmol}, 11 \%)$ was prepared from $8(0.038 \mathrm{~g}, 0.24 \mathrm{mmol})$ and $11 \mathrm{~b}(0.068 \mathrm{~g}, 0.24 \mathrm{mmol})$ as a white solid according to the general procedure. ${ }^{1} \mathrm{H}$ NMR (300 $\left.\mathrm{MHz}, \mathrm{CD}_{3} \mathrm{OD}\right) \delta 4.56(\mathrm{~d}, J=9 \mathrm{~Hz}, 1 \mathrm{H}), 4.14(\mathrm{~d}, J=6 \mathrm{~Hz}, 1 \mathrm{H}), 3.49(\mathrm{~s}, 3 \mathrm{H}), 2.74(\mathrm{~s}, 3 \mathrm{H})$, $1.92(\mathrm{~m}, 1 \mathrm{H}), 1.67(\mathrm{~m}, 7 \mathrm{H}), 1.22(\mathrm{~m}, 5 \mathrm{H}), 0.94(\mathrm{~m}, 7 \mathrm{H}) ;{ }^{13} \mathrm{C}$ NMR $\left(75 \mathrm{MHz}\right.$, DMSO- $\left.d_{6}\right)$ $\delta$ 183.8, 182.7, 171.7, 171.1, 169.1, 168.1, 61.3, 58.4, 40.7, 39.2, 39.1, 31.1, 30.0, 29.2, 26.9, 26.8, 26.7, 24.4, 15.8, 12.0; HRMS-FAB $\left(\mathrm{M}+\mathrm{Na}^{+}\right)$calcd for $\mathrm{C}_{20} \mathrm{H}_{32} \mathrm{~N}_{4} \mathrm{NaO}_{5} 431.2270$, found 431.2261 .

\section{3-(Hydroxymethylamino)-4-(L-isoleucyl-O-methyl-L-tyrosine methyl amide)-3- cyclobutene-1,2-dione (12c)}

Compound 12c $(0.054 \mathrm{~g}, 0.12 \mathrm{mmol}, 76 \%)$ was prepared from $\mathbf{8}(0.032 \mathrm{~g}, 0.16 \mathrm{mmol})$ and $11 \mathrm{c}(0.051 \mathrm{~g}, 0.16 \mathrm{mmol})$ according to the general procedure. ${ }^{1} \mathrm{H} \mathrm{NMR}\left(400 \mathrm{MHz}, \mathrm{CD}_{3} \mathrm{OD}\right)$ $\delta 7.11(\mathrm{~d}, J=8.5 \mathrm{~Hz}, 2 \mathrm{H}), 6.77(\mathrm{~d}, J=8.6 \mathrm{~Hz}, 2 \mathrm{H}), 4.60(\mathrm{dd}, J=9.6,5.5 \mathrm{~Hz}, 1 \mathrm{H}), 4.41(\mathrm{~d}$, $J=8.7 \mathrm{~Hz}, 1 \mathrm{H}), 3.75(\mathrm{~s}, 3 \mathrm{H}), 3.49(\mathrm{~s}, 3 \mathrm{H}), 3.06(\mathrm{dd}, J=13.8,5.5 \mathrm{~Hz}, 1 \mathrm{H}), 2.81(\mathrm{dd}, J=$ 13.9, $9.7 \mathrm{~Hz}, 1 \mathrm{H}), 2.73(\mathrm{~s}, 3 \mathrm{H}), 1.87(\mathrm{~m}, 1 \mathrm{H}), 1.53(\mathrm{~m}, 1 \mathrm{H}), 1.18(\mathrm{~m}, 1 \mathrm{H}), 0.90(\mathrm{~m}, 6$ $\mathrm{H}) ;{ }^{13} \mathrm{C}$ NMR $\left(100 \mathrm{MHz}, \mathrm{CD}_{3} \mathrm{OD}\right) \delta 179.1,178.5,172.4,171.3,165.9,165.7,158.6,129.8$, 128.6, 113.4, 62.0, 54.5, 54.2, 40.0, 37.0, 36.7, 24.9, 24.2, 14.1, 9.5; HRMS-FAB $\left(\mathrm{M}+\mathrm{Na}^{+}\right)$ calcd for $\mathrm{C}_{22} \mathrm{H}_{30} \mathrm{~N}_{4} \mathrm{O}_{6} \mathrm{Na} 469.2063$, found 469.2078 .

\section{3-(Hydroxymethylamino)-4-(L-isoleucyl-L-phenylalanine methyl amide)-3- cyclobutene-1,2- dione (12d)}

Compound 12d $(0.224 \mathrm{~g}, 0.54 \mathrm{mmol}, 75 \%)$ was prepared from $8(0.113 \mathrm{~g}, 0.72 \mathrm{mmol})$ and $11 \mathrm{~d}(0.210 \mathrm{~g}, 0.72 \mathrm{mmol})$ as a white solid according to the general procedure. ${ }^{1} \mathrm{H}$ NMR (300 $\left.\mathrm{MHz}, \mathrm{CD}_{3} \mathrm{OD}\right) \delta 7.21(\mathrm{~m}, 5 \mathrm{H}), 4.63(\mathrm{dd}, J=9.6,9.3 \mathrm{~Hz}, 1 \mathrm{H}), 4.43(\mathrm{~d}, J=8.6 \mathrm{~Hz}, 1 \mathrm{H}) 3.49$ $(\mathrm{s}, 3 \mathrm{H}), 3.12(\mathrm{dd}, J=6.3,5.3 \mathrm{~Hz}, 1 \mathrm{H}), 2.88(\mathrm{dd}, J=9.7,9.3 \mathrm{~Hz}, 1 \mathrm{H}), 2.71(\mathrm{~s}, 3 \mathrm{H}), 1.86(\mathrm{~m}$, $1 \mathrm{H}), 1.52(\mathrm{~m}, 1 \mathrm{H}), 1.16(\mathrm{~m}, 1 \mathrm{H}), 0.90(\mathrm{~m}, 6 \mathrm{H}) ;{ }^{13} \mathrm{C} \mathrm{NMR}\left(75 \mathrm{MHz}, \mathrm{CD}_{3} \mathrm{OD}\right) \delta 179.6,178.9$, 172.7, 171.7, 166.4, 166.2, 137.2, 129.2, 128.4, 126.7, 62.3, 54.9, 40.4, 38.1, 37.3, 25.4, 24.5, 14.5, 9.92; HRMS-FAB $\left(\mathrm{M}+\mathrm{Na}^{+}\right)$calcd for $\mathrm{C}_{21} \mathrm{H}_{28} \mathrm{~N}_{4} \mathrm{NaO}_{5} 439.1957$, found 439.1968.

\section{3-(Hydroxymethylamino)-4-(L-isoleucyl-L-phenylglycine methyl amide)-3- cyclobutene-1,2- dione (12e)}

Compound 12e $(0.021 \mathrm{~g}, 0.053 \mathrm{mmol}, 65 \%)$ was prepared from $\mathbf{8}(0.016 \mathrm{~g}, 0.08 \mathrm{mmol})$ and $11 \mathrm{e}(0.023 \mathrm{~g}, 0.083 \mathrm{mmol})$ according to the general procedure. ${ }^{1} \mathrm{H} \mathrm{NMR}\left(300 \mathrm{MHz}, \mathrm{CD}_{3} \mathrm{OD}\right)$ $\delta 7.42(\mathrm{~m}, 2 \mathrm{H}), 7.35(\mathrm{~m}, 3 \mathrm{H}), 5.42(\mathrm{~s}, 1 \mathrm{H}), 4.6(\mathrm{~d}, J=6 \mathrm{~Hz}, 1 \mathrm{H}), 3.47(\mathrm{~s}, 3 \mathrm{H}), 2.73(\mathrm{~s}, 3 \mathrm{H})$, $1.96(\mathrm{~m}, 1 \mathrm{H}), 1.63(\mathrm{~m}, 1 \mathrm{H}), 1.26(\mathrm{~m}, 1 \mathrm{H}), 1.0(\mathrm{~m}, 6 \mathrm{H}) ;{ }^{13} \mathrm{C} \mathrm{NMR}\left(75 \mathrm{MHz}, \mathrm{CD}_{3} \mathrm{OD}\right) \delta$ 179.1, 178.5, 171.1, 171.0, 166.1, 165.9, 137.3, 128.4, 128.0, 127.2, 61.8, 57.3, 40.0, 37.7, 25.0, 24.2, 14.1, 9.8; HRMS-FAB $\left(\mathrm{M}+\mathrm{Na}^{+}\right)$calcd for $\mathrm{C}_{20} \mathrm{H}_{26} \mathrm{~N}_{4} \mathrm{O}_{5} \mathrm{Na} 425.1801$, found 425.1810 . 


\section{3-(Hydroxymethylamino)-4-(L-isoleucyl-L-tryptophan methyl amide)-3-cyclobutene- 1,2- dione (12f)}

Compound $\mathbf{1 2 f}(0.057 \mathrm{~g}, 0.125 \mathrm{mmol}, 78 \%)$ was prepared from $\mathbf{8}(0.032 \mathrm{~g}, 0.16 \mathrm{mmol})$ and $11 f(0.053 \mathrm{~g}, 0.16 \mathrm{mmol})$ according to the general procedure. ${ }^{1} \mathrm{H}$ NMR $\left(400 \mathrm{MHz}, \mathrm{CD}_{3} \mathrm{OD}\right)$ $\delta 7.57(\mathrm{~d}, J=7.8 \mathrm{~Hz}, 1 \mathrm{H}), 7.31(\mathrm{~d}, J=8.1 \mathrm{~Hz}, 1 \mathrm{H}), 7.07(\mathrm{~m}, 2 \mathrm{H}), 6.99(\mathrm{~m}, 1 \mathrm{H}), 4.66(\mathrm{dd}$, $J=8.1,6.4 \mathrm{~Hz}, 1 \mathrm{H}), 4.46(\mathrm{~d}, J=8.2 \mathrm{~Hz}, 1 \mathrm{H}), 3.47(\mathrm{~s}, 3 \mathrm{H}), 3.25(\mathrm{dd}, J=14.6,6.3 \mathrm{~Hz}, 1 \mathrm{H})$, $3.11(\mathrm{dd}, J=14.5,8.1 \mathrm{~Hz}, 1 \mathrm{H}), 2.67(\mathrm{~s}, 3 \mathrm{H}), 1.86(\mathrm{~m}, 1 \mathrm{H}), 1.50(\mathrm{~m}, 1 \mathrm{H}), 1.13(\mathrm{~m}, 1 \mathrm{H}), 0.88$ $(\mathrm{m}, 6 \mathrm{H}) ;{ }^{13} \mathrm{C} \mathrm{NMR}\left(100 \mathrm{MHz}, \mathrm{CD}_{3} \mathrm{OD}\right) \delta 179.1,178.5,172.8,171.3,166.0,165.8,136.6$, 127.3, 123.3, 120.9, 118.4, 117.9, 110.9, 109.3, 62.0, 54.3, 40.0, 37.3, 27.8, 25.0, 24.1, 14.1, 9.7; HRMS-FAB $\left(\mathrm{M}+\mathrm{Na}^{+}\right)$calcd for $\mathrm{C}_{23} \mathrm{H}_{29} \mathrm{~N}_{5} \mathrm{O}_{5} \mathrm{Na}$ 478.2066, found 478.2060.

\section{3-(Hydroxymethylamino)-4-(L-isoleucyl-L-leucine methyl amide)-3-cyclobutene-1,2- dione $(12 \mathrm{~g})$}

Compound 12g (0.051 g, $0.133 \mathrm{mmol}, 82 \%)$ was prepared from $8(0.032 \mathrm{~g}, 0.16 \mathrm{mmol})$ and $11 \mathrm{~g}(0.042 \mathrm{~g}, 0.163 \mathrm{mmol})$ according to the general procedure. ${ }^{1} \mathrm{H}$ NMR $\left(400 \mathrm{MHz}, \mathrm{CD}_{3} \mathrm{OD}\right)$ $\delta 4.57(\mathrm{~d}, J=8.1 \mathrm{~Hz}, 1 \mathrm{H}), 4.41(\mathrm{dd}, J=9.4,5.4 \mathrm{~Hz}, 1 \mathrm{H}), 3.50(\mathrm{~s}, 3 \mathrm{H}), 2.74(\mathrm{~s}, 3 \mathrm{H}), 1.96$ $(\mathrm{m}, 1 \mathrm{H}), 1.63(\mathrm{~m}, 3 \mathrm{H}), 1.53(\mathrm{~m}, 1 \mathrm{H}), 1.22(\mathrm{~m}, 1 \mathrm{H}), 0.94(\mathrm{~m}, 12 \mathrm{H}) ;{ }^{13} \mathrm{C} \mathrm{NMR}(100 \mathrm{MHz}$, $\left.\mathrm{CD}_{3} \mathrm{OD}\right) \delta 179.1,178.6,173.5,171.6,166.3,165.9,61.9,51.9,40.6,40.1,37.6,25.0,24.5$, 24.3, 22.0, 20.7, 14.3, 9.9; HRMS-FAB $\left(\mathrm{M}+\mathrm{H}^{+}\right)$calcd for $\mathrm{C}_{18} \mathrm{H}_{31} \mathrm{~N}_{4} \mathrm{O}_{5} 383.2295$, found 383.2304 .

\section{3-(Hydroxymethylamino)-4-(L-leucyl-L-tert-leucine methyl amide)-3-cyclobutene- 1,2-dione (12h)}

Compound 12h $(0.028 \mathrm{~g}, 0.074 \mathrm{mmol}, 74 \%)$ was prepared from $8(0.02 \mathrm{~g}, 0.1 \mathrm{mmol})$ and 11h $(0.026 \mathrm{~g}, 0.1 \mathrm{mmol})$ according to the general procedure. ${ }^{1} \mathrm{H}$ NMR $(400 \mathrm{MHz}$, DMSO$\left.d_{6}\right) \delta 4.76(\mathrm{br} \mathrm{s}, 1 \mathrm{H}), 4.2(\mathrm{~d}, J=9.6 \mathrm{~Hz}, 1 \mathrm{H}), 3.38(\mathrm{~s}, 3 \mathrm{H}), 2.57(\mathrm{~d}, J=4.4 \mathrm{~Hz}, 3 \mathrm{H}), 1.76(\mathrm{~m}$, $1 \mathrm{H}), 1.62(\mathrm{~m}, 1 \mathrm{H}), 1.51(\mathrm{~m}, 1 \mathrm{H}), 0.87(\mathrm{~s}, 15 \mathrm{H}) ;{ }^{13} \mathrm{C} \mathrm{NMR}\left(75 \mathrm{MHz}, \mathrm{CD}_{3} \mathrm{OD}\right) \delta 179.8,178.9$, 172.7, 171.9, 166.5, 166.3, 61.3, 56.6, 41.1, 40.4, 34.4, 26.1, 25.0, 24.9, 22.5, 20.8; HRMSFAB $\left(\mathrm{M}+\mathrm{Na}^{+}\right)$calcd for $\mathrm{C}_{18} \mathrm{H}_{30} \mathrm{~N}_{4} \mathrm{O}_{5} \mathrm{Na} 405.2114$, found 405.2105 .

3-(L-Leucyl-L-tert-leucine methyl amide)-4-methoxy-3-cyclobutene-1,2-dione (13)

To a stirred solution of $2(0.021 \mathrm{~g}, 0.15 \mathrm{mmol})$ in $\mathrm{MeOH}, 11 \mathrm{~h}(0.042 \mathrm{~g}, 0.165 \mathrm{mmol})$ was added and the mixture was heated at reflux overnight. The solvent was evaporated and the crude product was purified by column chromatography $\left(3: 97 \mathrm{MeOH} / \mathrm{CH}_{2} \mathrm{Cl}_{2}\right.$ ) giving compound $13(0.052 \mathrm{~g}, 0.136 \mathrm{mmol}, 95 \%) .{ }^{1} \mathrm{H}$ NMR $\left(300 \mathrm{MHz}, \mathrm{CD}_{3} \mathrm{OD}\right) \delta 4.40$ (s, $\left.4 \mathrm{H}\right), 4.25$ (d, $J=9$ $\mathrm{Hz}, 1 \mathrm{H}), 2.74(\mathrm{~s}, 3 \mathrm{H}), 1.68(\mathrm{~m}, 3 \mathrm{H}), 0.99(\mathrm{~d}, J=6 \mathrm{~Hz}, 15 \mathrm{H}) ;{ }^{13} \mathrm{C} \mathrm{NMR}\left(75 \mathrm{MHz}, \mathrm{CD}_{3} \mathrm{OD}\right)$ $\delta 188.7,187.9,184.2,183.7,178.0,176.9,173.1,172.6,172.0,171.9,171.4,60.8,60.7,59.9$, 56.8, 56.1, 25.6, 24.6, 24.5, 22.1, 20.0; HRMS-ESI $\left(\mathrm{M}+\mathrm{Na}^{+}\right)$calcd for $\mathrm{C}_{18} \mathrm{H}_{29} \mathrm{~N}_{3} \mathrm{O}_{5} \mathrm{Na}$ 390.2005, found 390.2010 .

\section{3-Hydroxy-4-(L-leucyl-L-tert-leucine methyl amide)-3-cyclobutene-1,2-dione (14)}

To a stirred solution of $\mathbf{1 3}(0.05 \mathrm{~g}, 0.136 \mathrm{mmol})$ in $\mathrm{MeOH}(3 \mathrm{~mL}), 0.15 \mathrm{~N} \mathrm{HCl}(1 \mathrm{~mL})$ was added and the mixture was heated at reflux overnight. The solvent was evaporated and the crude product was purified by column chromatography $\left(3: 97 \mathrm{MeOH} / \mathrm{CH}_{2} \mathrm{Cl}_{2}\right)$ giving $14(0.032$ $\mathrm{g}, 0.091 \mathrm{mmol}, 67 \%) .{ }^{1} \mathrm{H}$ NMR $\left(300 \mathrm{MHz}, \mathrm{CD}_{3} \mathrm{OD}\right) \delta 4.22(\mathrm{~s}, 1 \mathrm{H}), 3.32(\mathrm{~s}, 1 \mathrm{H}), 2.74(\mathrm{~s}, 3$ $\mathrm{H}), 1.69$ (m, $3 \mathrm{H}), 0.96$ (s, $15 \mathrm{H}) ;{ }^{13} \mathrm{C}$ NMR $\left(75 \mathrm{MHz}, \mathrm{CD}_{3} \mathrm{OD}\right) \delta 196.3,187.8,180.7,172.5$, 171.9, 61.3, 55.8, 40.6, 34.5, 26.1, 25.1, 24.8, 22.5, 20.9; HRMS-ESI $\left(\mathrm{M}-\mathrm{H}^{+}\right)$calcd for $\mathrm{C}_{17} \mathrm{H}_{26} \mathrm{~N}_{3} \mathrm{O}_{5} 352.1872$, found 352.1880 . 


\section{3-(Hydroxymethylamino)-2-(L-isoleucine methylester)-4-thioxo-2-cyclobuten-1-one (15)}

Compound 6a $(0.100 \mathrm{~g}, 0.370 \mathrm{mmol})$ was dissolved in $2 \mathrm{~mL}$ of $\mathrm{CH}_{2} \mathrm{Cl}_{2}$ and allowed to stir while Lawesson's reagent $(0.150 \mathrm{~g}, 0.370 \mathrm{mmol})$ was added. The reaction was monitored by TLC until all the starting material had been consumed. The solvent was then evaporated and the crude material was purified by column chromatography $\left(5: 95 \mathrm{MeOH} / \mathrm{CH}_{2} \mathrm{Cl}_{2}\right)$ providing 15 as a yellow solid $(0.062 \mathrm{~g}, 0.23 \mathrm{mmol}, 62 \%) .{ }^{1} \mathrm{H}-\mathrm{NMR}\left(300 \mathrm{MHz}, \mathrm{CDCl}_{3}\right) \delta 9.02$ (br s, 1 H), 8.19 (br s, $1 \mathrm{H}), 5.93$ (br s, $1 \mathrm{H}), 3.76(\mathrm{~s}, 3 \mathrm{H}), 3.67$ (s, $3 \mathrm{H}), 2.20$ (m, $1 \mathrm{H}), 2.07$ (m, $1 \mathrm{H})$, $1.48(\mathrm{~m}, 1 \mathrm{H}), 1.26(\mathrm{~m}, 1 \mathrm{H}), 1.00(\mathrm{~d}, J=6.8 \mathrm{~Hz}, 3 \mathrm{H}), 0.93(\mathrm{t}, J=7.3 \mathrm{~Hz}, 3 \mathrm{H}) ;{ }^{13} \mathrm{C}$ NMR $(75$ $\left.\mathrm{MHz}, \mathrm{CDCl}_{3}\right) \delta 205.4,201.6,170.9,170.8,170.6,61.2,52.9,39.4,31.6,25.3,15.8,12.2$; ESIMS $\left(\mathrm{M}+\mathrm{H}^{+}\right)$calcd for $\mathrm{C}_{12} \mathrm{H}_{19} \mathrm{~N}_{2} \mathrm{O}_{3} \mathrm{~S}_{2} 271.1294$, found 271.1287.

\section{3-(Hydroxymethylamino)-2-(L-isoleucyl-L-phenylalanine methylamide)-4-thioxo-2- cyclobuten-1-one (16)}

Compound $16(0.093 \mathrm{~g}, 0.216 \mathrm{mmol}, 71 \%)$ was prepared as a yellow solid according to the procedure used to prepare 15 starting from $12 \mathrm{~d}(0.127 \mathrm{~g}, 0.305 \mathrm{mmol})$ and Lawesson's reagent $(0.123 \mathrm{~g}, 0.304 \mathrm{mmol})$. The crude material was purified by column chromatography (3:97 $\mathrm{MeOH} / \mathrm{CH}_{2} \mathrm{Cl}_{2}$ ). ${ }^{1} \mathrm{H}-\mathrm{NMR}\left(300 \mathrm{MHz}, \mathrm{CD}_{3} \mathrm{OD}\right) 7.15(\mathrm{~m}, 5 \mathrm{H}), 5.56(\mathrm{~d}, J=7.6 \mathrm{~Hz}, 1 \mathrm{H}), 4.90$ (s, $3 \mathrm{H}), 4.68(\mathrm{~m}, 1 \mathrm{H}), 3.63(\mathrm{~s}, 2 \mathrm{H}), 3.10(\mathrm{~m}, 1 \mathrm{H}), 2.72(\mathrm{~d}, J=0.6 \mathrm{~Hz}, 3 \mathrm{H}), 1.91(\mathrm{~m}, 1 \mathrm{H})$, $1.49(\mathrm{~m}, 1 \mathrm{H}) 1.17(\mathrm{~m}, 1 \mathrm{H}) 0.87(\mathrm{~m}, 6 \mathrm{H}) ;{ }^{13} \mathrm{C} \mathrm{NMR}\left(75 \mathrm{MHz}, \mathrm{CD}_{3} \mathrm{OD}\right) \delta 206.7,204.0,172.7$, 171.1, 170.7, 170.4, 137.1, 129.3, 128.4, 126.5, 60.8, 54.9, 38.3, 37.6, 30.4, 25.5, 24.4, 14.5, 10.3; ESI-MS $\left(\mathrm{M}+\mathrm{Na}^{+}\right)$calcd for $\mathrm{C}_{21} \mathrm{H}_{28} \mathrm{~N}_{4} \mathrm{O}_{4} \mathrm{SNa} 455.1729$, found 455.1738 .

\section{3-(Hydroxymethylamino)-2-(L-isoleucyl-L-leucine methyl amide)-4-thioxo-2- cyclobuten-1- one (17)}

Compound 17 was prepared as a yellow solid $(0.013 \mathrm{~g}, 0.032 \mathrm{mmol}, 59 \%)$ from $12 \mathrm{~g}(0.021 \mathrm{~g}$, $0.055 \mathrm{mmol})$ and Lawesson's reagent $(0.022 \mathrm{~g}, 0.055 \mathrm{mmol})$ according to the procedure used to prepare compound $\mathbf{1 5}$. The crude material was purified by column chromatography (1.3:98.7 $\mathrm{MeOH} / \mathrm{CH}_{2} \mathrm{Cl}_{2}$ ). ${ }^{1} \mathrm{H}$ NMR $\left(300 \mathrm{MHz}, \mathrm{CD}_{3} \mathrm{OD}\right) \delta 5.67$ (d, $\left.J=6.8 \mathrm{~Hz}, 1 \mathrm{H}\right), 4.39$ (dd, $J=9.5$, $5.2 \mathrm{~Hz}, 1 \mathrm{H}), 3.63(\mathrm{~s}, 3 \mathrm{H}), 2.73(\mathrm{~s}, 3 \mathrm{H}), 2.00(\mathrm{~m}, 1 \mathrm{H}), 1.56(\mathrm{~m}, 4 \mathrm{H}), 1.24(\mathrm{~m}, 1 \mathrm{H}), 0.96(\mathrm{~m}$, $12 \mathrm{H}) ;{ }^{13} \mathrm{C}$ NMR (75 MHz, $\left.\mathrm{CD}_{3} \mathrm{OD}\right) \delta 206.6,203.9,173.5,171.2,170.9,170.2,60.5,51.9$, 40.6, 37.9, 29.9, 24.9, 24.5, 23.9, 22.0, 20.5, 14.2, 10.2; HRMS-FAB $\left(\mathrm{M}+\mathrm{Na}^{+}\right)$calcd for $\mathrm{C}_{18} \mathrm{H}_{30} \mathrm{~N}_{4} \mathrm{O}_{4} \mathrm{SNa}$ 421.1885, found 421.1880 .

\section{3-(Hydroxymethylamino)-2-(L-leucyl-L-tert-leucine methyl amide)-4-thioxo-2- cyclobuten-1- one (18)}

Compound 18 was prepared as a yellow solid $(0.014 \mathrm{~g}, 0.035 \mathrm{mmol}, 41 \%)$ from $12 \mathrm{~h}(0.033 \mathrm{~g}$, $0.086 \mathrm{mmol})$ and Lawesson's reagent $(0.035 \mathrm{~g}, 0.086 \mathrm{mmol})$ according to the procedure used to prepare compound 15 . The crude material was purified by column chromatography (1.3:98.7 $\mathrm{MeOH} / \mathrm{CH}_{2} \mathrm{Cl}_{2}$ ). ${ }^{1} \mathrm{H}$ NMR (400 MHz, CD $\left.{ }_{3} \mathrm{OD}\right) \delta 5.92(\mathrm{~s}, 1 \mathrm{H}), 4.21(\mathrm{~s}, 1 \mathrm{H}), 3.62(\mathrm{~s}, 3 \mathrm{H})$, $2.74(\mathrm{~s}, 3 \mathrm{H}), 1.72(\mathrm{~m}, 3 \mathrm{H}), 0.98(\mathrm{~m}, 15 \mathrm{H}) ;{ }^{13} \mathrm{C} \mathrm{NMR}\left(100 \mathrm{MHz}, \mathrm{CD}_{3} \mathrm{OD}\right) \delta$ 206.1, 203.5, $171.7,171.4,170.7,170.0,61.2,54.8,40.7,34.2,30.2,25.9,24.8,24.5,22.2$, 20.6; LRMSFAB $\left(\mathrm{M}+\mathrm{Na}^{+}\right)$calcd for $\mathrm{C}_{18} \mathrm{H}_{30} \mathrm{~N}_{4} \mathrm{O}_{4} \mathrm{SNa} 421.0$, found 421.1 .

\section{3,4-Di-(L-phenylalanine methyl ester)-3-cyclobutene-1,2-dione (19)}

To a stirred solution of L-phenylalanine methyl ester $\mathrm{HCl}$ salt $(0.646 \mathrm{~g}, 3.0 \mathrm{mmol})$ in $\mathrm{MeOH}$ $(10 \mathrm{ml}), \mathrm{KOH}(0.168 \mathrm{~g}, 3.0 \mathrm{mmol})$ and compound $7(0.256 \mathrm{~g}, 1.13 \mathrm{mmol})$ were added. Formation of a white precipitate was observed. The mixture was stirred for $3 \mathrm{~h}$ at room temperature, the solvent was evaporated, EtOAc was added and the solution was washed with $\mathrm{H}_{2} \mathrm{O}$. The organic layer was dried over $\mathrm{MgSO}_{4}$, and the solvent was evaporated. The crude product was recrystallized from $\mathrm{MeOH}$. The resulting white crystals were washed with cold $\mathrm{MeOH}$ and dried in vacuo to give 19 as a white solid $(0.363 \mathrm{~g}, 0.831 \mathrm{mmol}, 74 \%) .{ }^{1} \mathrm{H}$ NMR 
(400 MHz, DMSO- $\left.d_{6}\right) \delta 7.91(\mathrm{br} \mathrm{s}, 1 \mathrm{H}), 7.27(\mathrm{~m}, 6 \mathrm{H}), 7.14(\mathrm{~d}, J=6.4 \mathrm{~Hz}, 4 \mathrm{H}), 5.00(\mathrm{~d}, J=$ $6.1 \mathrm{~Hz}, 2 \mathrm{H}), 3.70(\mathrm{~s}, 6 \mathrm{H}), 3.17(\mathrm{dd}, J=13.5,4.9 \mathrm{~Hz}, 2 \mathrm{H}), 3.06(\mathrm{~m}, 2 \mathrm{H}) ;{ }^{13} \mathrm{C}$ NMR $(100$ MHz, DMSO- $\left.d_{6}\right) \delta 183.3,171.6,167.5,136.4,129.8,128.9,127.3,57.2,55.3,52.8$; HRMSESI $\left(\mathrm{M}+\mathrm{H}^{+}\right)$calcd for $\mathrm{C}_{24} \mathrm{H}_{25} \mathrm{~N}_{2} \mathrm{O}_{6} 437.1713$, found 437.1722 .

\section{2,3-Bis(L-phenylalanine methyl ester)-4-thioxo-2-cyclobuten-1-one (20)}

To a stirred solution of $\mathbf{1 9}(0.112 \mathrm{~g}, 0.257 \mathrm{mmol})$ in dry $\mathrm{CH}_{2} \mathrm{Cl}_{2}(5 \mathrm{ml})$, Lawesson's reagent $(0.021 \mathrm{~g}, 0.052 \mathrm{mmol})$ was added. After TLC analysis indicated that the reaction was complete, the crude product was purified by column chromatography (gradient of $0.25-1.0 \% \mathrm{MeOH} /$ $\mathrm{CH}_{2} \mathrm{Cl}_{2}$ ) to yield compound 20 as a yellow solid $(0.038 \mathrm{~g}, 0.084 \mathrm{mmol}, 40 \%) .{ }^{1} \mathrm{H}$ NMR (400 MHz, DMSO- $\left.d_{6}\right) \delta 8.76(\mathrm{~d}, J=7.9 \mathrm{~Hz}, 1 \mathrm{H}), 8.31(\mathrm{~d}, J=9.1 \mathrm{~Hz}, 1 \mathrm{H}), 7.21(\mathrm{~m}, 10 \mathrm{H}), 6.12$ $(\mathrm{dd}, J=15.0,6.3 \mathrm{~Hz}, 1 \mathrm{H}), 5.01(\mathrm{dd}, J=12.7,6.7 \mathrm{~Hz}, 1 \mathrm{H}), 3.73(\mathrm{~s}, 3 \mathrm{H}), 3.70(\mathrm{~s}, 3 \mathrm{H}), 3.18$ (m, $4 \mathrm{H}) ;{ }^{13} \mathrm{C}$ NMR (100 MHz, DMSO- $\left.d_{6}\right) \delta 204.0,180.4,172.0,171.4,170.8,168.9,136.0$, $129.8,129.7,129.0,128.9,127.5,127.4,58.1,55.8,53.1,52.9$; HRMS-ESI $\left(\mathrm{M}+\mathrm{H}^{+}\right)$calcd for $\mathrm{C}_{24} \mathrm{H}_{25} \mathrm{~N}_{2} \mathrm{O}_{5} \mathrm{~S} 453.1484$, found 453.1490 .

\section{3-(Hydroxymethylamino)-2-(L-phenylalanine methyl ester)-4-thioxo-2-cyclobuten-1- one (21)}

To a stirred solution of $6 \mathbf{e}(0.171 \mathrm{~g}, 0.562 \mathrm{mmol})$ in dry $\mathrm{CH}_{2} \mathrm{Cl}_{2}(5 \mathrm{ml})$, Lawesson's reagent $(0.227 \mathrm{~g}, 0.561 \mathrm{mmol})$ was added. After TLC analysis indicated that the reaction was complete, the solvent was evaporated and the crude product was purified by column chromatography $\left(\mathrm{CH}_{2} \mathrm{Cl}_{2}\right)$ to yield compound 21 as a yellow solid $(0.104 \mathrm{~g}, 0.325 \mathrm{mmol}, 58 \%) .{ }^{1} \mathrm{H} \mathrm{NMR}(400$ $\left.\mathrm{MHz}, \mathrm{DMSO}-d_{6}\right) \delta 8.87$ (br s, $\left.1 \mathrm{H}\right), 8.56(\mathrm{br} \mathrm{s}, 1 \mathrm{H}), 7.24(\mathrm{~m}, 5 \mathrm{H}), 6.23(\mathrm{t}, J=6.0,1 \mathrm{H}), 3.72$ (s, $3 \mathrm{H}), 3.50$ (s, $3 \mathrm{H}), 3.21(\mathrm{~m}, 2 \mathrm{H}) ;{ }^{13} \mathrm{C}$ NMR (100 MHz, DMSO- $\left.d_{6}\right) \delta 206.5,203.2,171.0$, 170.7, 170.6, 135.7, 129.9, 129.0, 127.5, 56.3, 53.1, 30.8; HRMS-FAB $\left(\mathrm{M}+\mathrm{Na}^{+}\right)$calcd for $\mathrm{C}_{15} \mathrm{H}_{16} \mathrm{~N}_{2} \mathrm{O}_{4} \mathrm{SNa} 343.0729$, found 343.0740.

\section{Procedure for the Assay of MMP-1}

MMP-1, prepared from a culture medium of human rheumatoid synovial fibroblasts, was obtained from Calbiochem. The assays were based on the enzymatic hydrolysis of the peptide substrate Dnp-Pro-Cha-Gly-Cys(Me)-His-Ala-Lys(Nma)- $\mathrm{NH}_{2},{ }^{18}$ using the procedure described by Le Diguarher. ${ }^{19}$ This is a fluorescence quenching assay in which $N$ methylanthranilic acid (Nma) is the fluorophore and dinitrophenyl (Dnp) is the quencher.

Pro-MMP-1 was dissolved in assay buffer ( $200 \mathrm{mM} \mathrm{NaCl}, 50 \mathrm{mM}$ Tris, $5 \mathrm{mM} \mathrm{CaCl}_{2}, 20 \mu \mathrm{M}$ $\mathrm{ZnSO}_{4}, 0.05 \%$ Brij 35, $\mathrm{pH} 7.6$ ) at a concentration of $1.25 \mu \mathrm{g} / \mathrm{mL}$. APMA solution ( $p$ aminophenylmercuric acetate, $2 \mathrm{mM}$ in $0.1 \mathrm{~N} \mathrm{NaOH}$ ) was prepared. Proenzyme activation was performed by mixing the proenzyme solution and the APMA solution in a 10:1 ratio. This reaction was incubated at $37^{\circ} \mathrm{C}$ for $30 \mathrm{~min}$ and subsequently transferred to ice and then to a freezer. The substrate was dissolved in DMSO at a concentration of $2 \mathrm{mM}$, and then diluted to $0.2 \mathrm{mM}$ with $\mathrm{H}_{2} \mathrm{O}$. Inhibitors were dissolved in a 10:90 DMSO/buffer solution. Fluorescence measurements were performed in 96-well plates by incubating assay buffer $(76 \mu \mathrm{l})$, activated enzyme $(4 \mu \mathrm{l})$, and the inhibitor solution (or buffer for the blank) $(10 \mu \mathrm{l})$ at $37^{\circ} \mathrm{C}$ for $30 \mathrm{~min}$ and then adding the substrate $(10 \mu \mathrm{l})$ to the wells. The change in fluorescence was measured using excitation and emission wavelengths of $340 \mathrm{~nm}$ and $460 \mathrm{~nm}$, respectively. $\mathrm{IC}_{50}$ values were calculated using the commercial graphing package Grafit (Erithacus Software Ltd.). Data was obtained for assays with at least 5 different concentrations, in duplicate, of each inhibitor.

\section{Supplementary Material}

Refer to Web version on PubMed Central for supplementary material. 


\section{Acknowledgements}

We thank Mr. Jian Xie for helpful discussions. This research was supported by the NIH NIGMS (Grant R01 GM057327).

\section{References}

1. Whittaker M, Floyd CD, Brown P, Gearing AJH. Chem Rev 1999;99:2735-2776. [PubMed: 11749499]

2. Jones CB, Sane DC, Herrington DM. Cardiovasc Res 2003;59:812-823. [PubMed: 14553821]

3. Chakraborti S, Mandal M, Das S, Mandal A, Chakraborti T. Mol Cell Biochem 2003;253:269-285. [PubMed: 14619979]

4. Westermarck J, Kahari VM. FASEB J 1999;13:781-792. [PubMed: 10224222]

5. Fisher C, Gilbertson-Beadling S, Powers EA, Petzold G, Poorman R, Mitchell MA. Dev Biol 1994;162:499-510. [PubMed: 7512058]

6. Billinghurst RC, Dahlberg L, Ionescu M, Reiner A, Bourne R, Rorabeck C, Mitchell P, Hambor J, Diekmann O, Tschesche H, Chen J, Van Wart H, Poole AR. J Clin Invest 1997;7:1534-1545. [PubMed: 9119997]

7. Jackson C, Nguyen M, Arkell J, Sambrook P. Inflamm Res 2001;50:183-186. [PubMed: 11392606]

8. Lee W, Aitken S, Sodek J, McCulloch CA. J Periodont Res 1995;30:23-33. [PubMed: 7722844]

9. Liedtke W, Cannella B, Mazzaccaro RJ, Clements JM, Miller KM, Wucherpfennig KW, Gearing AJH, Raine CS. Ann Neurol 1998;44:35-46. [PubMed: 9667591]

10. Xie J, Comeau AB, Seto CT. Org Lett 2004;6:83-86. [PubMed: 14703356]

11. Kim CU, Misco PF. Tetrahedron Lett 1992;33:3961-3962.

12. Sato K, Seio K, Sekine M. J Am Chem Soc 2002;124:12715-12724. [PubMed: 12392419]

13. Shinada T, Nakagawa Y, Hayashi K, Corzo G, Nakajima T, Ohfune Y. Amino Acids 2003;24:293301. [PubMed: 12707812]

14. Sun L, Chiu D, Kowal D, Simon R, Smeyne M, Zukin RS, Olney J, Baudy R, Lin S. J Pharmacol Exp Ther 2004;310:563-570. [PubMed: 15075380]

15. Butera JA, Antane MM, Antane SA, Argentieri TM, Freeden C, Graceffa RF, Hirth BH, Jenkins D, Lennox JR, Matelan E, Norton NW, Quagliato D, Sheldon JH, Spinelli W, Warga D, Wojdan A, Woods M. J Med Chem 2000;43:1187-1202. [PubMed: 10737752]

16. Lovejoy B, Welch AR, Carr S, Luong C, Broka C, Hendricks T, Campbell JA, Walker KAM, Martin R, Van Wart H, Browner MF. Nat Struct Biol 1999;6:217-221. [PubMed: 10074939]

17. Lim NC, Morton MD, Jenkins HA, Bruckner C. J Org Chem 2003;68:9233-9241. [PubMed: 14629141]

18. Bickett DM, Green MD, Berman J, Dezube M, Howe AS, Brown PJ, Roth JT, McGeehan GM. Anal Biochem 1993;212:58-64. [PubMed: 8368516]

19. Le Diguarher T, Chollet AM, Bertrand M, Hennig P, Raimbaud E, Sabatini M, Guilbaud N, Pierre A, Tucker GC, Casara P. J Med Chem 2003;46:3840-3852. [PubMed: 12930146]

20. Borkakoti N, Winkler FK, Williams DH, D’Arcy A, Broadhurst MJ, Brown PA, Johnson WH, Murray EJ. Nat Struct Biol 1994;1:106-110. [PubMed: 7656013]

21. Solans X, Aguilo M, Gleizes A, Faus J, Julve M, Verdaguer M. Inorg Chem 1990;29:775-784.

22. An X-ray crystal structure of a hydroxamic acid/zinc complex shows that the bite angle in this complex is 81.1 ${ }^{\circ}$. Ruf M, Weis K, Brasack I, Vahrenkamp H. Inorg Chim Acta 1996;250:271-281. For comparison, we used HyperChem 3D to calculate the bite angle in a zinc complex of the squaric acid/ hydroxamic acid hybrids, which was calculated to be $117.9^{\circ}$

23. Reich R, Katz Y, Hadar R, Breuer E. Clin Cancer Res 2005;11:3925-3929. [PubMed: 15897594]

24. Puerta DT, Lewis JA, Cohen SM. J Am Chem Soc 2004;126:8388-8389. [PubMed: 15237990]

25. Kortylewicz ZP, Galardy RE. J Med Chem 1990;33:263-273. [PubMed: 2153207]

26. Reichard GA, Stengone C, Paliwal S, Mergelsberg I, Majmundar S, Wang C, Tiberi R, McPhail AT, Piwinski JJ, Shih NY. Org Lett 2003;5:4249-4251. [PubMed: 14601972] 

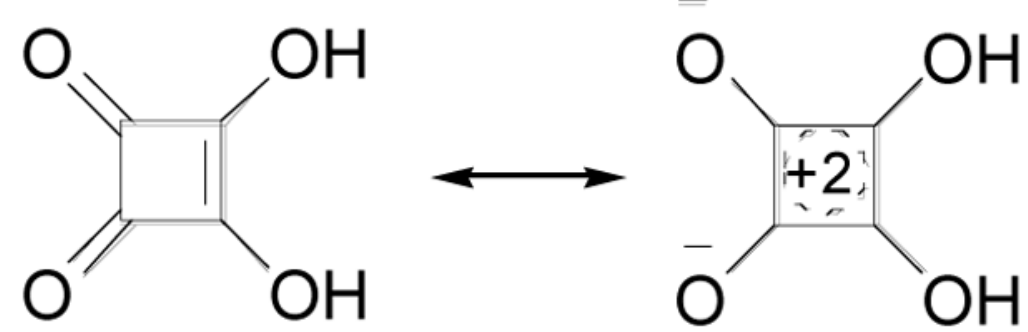

FIGURE 1.

Resonance structures of squaric acid. 

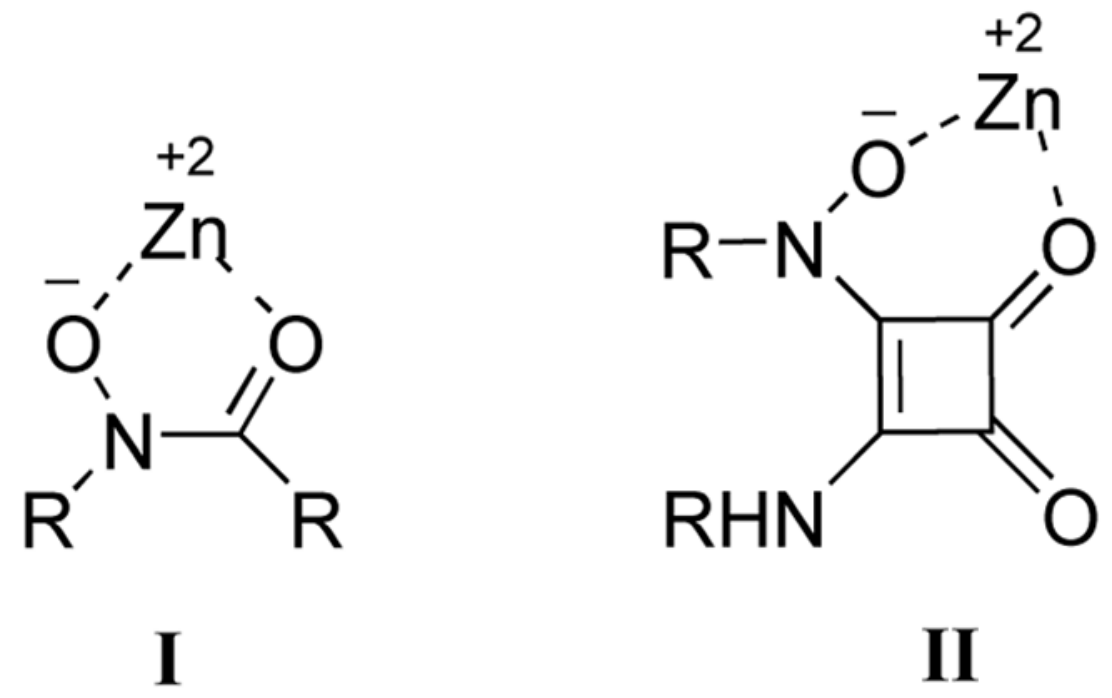

FIGURE 2.

Known binding mode of hydroxamic acid I versus proposed binding mode by squaric acid derivative II. 

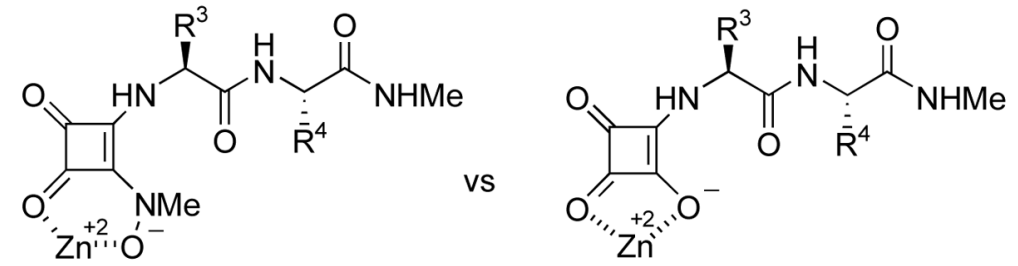

FIGURE 3.

6-membered vs. 5-membered zinc chelation models. 

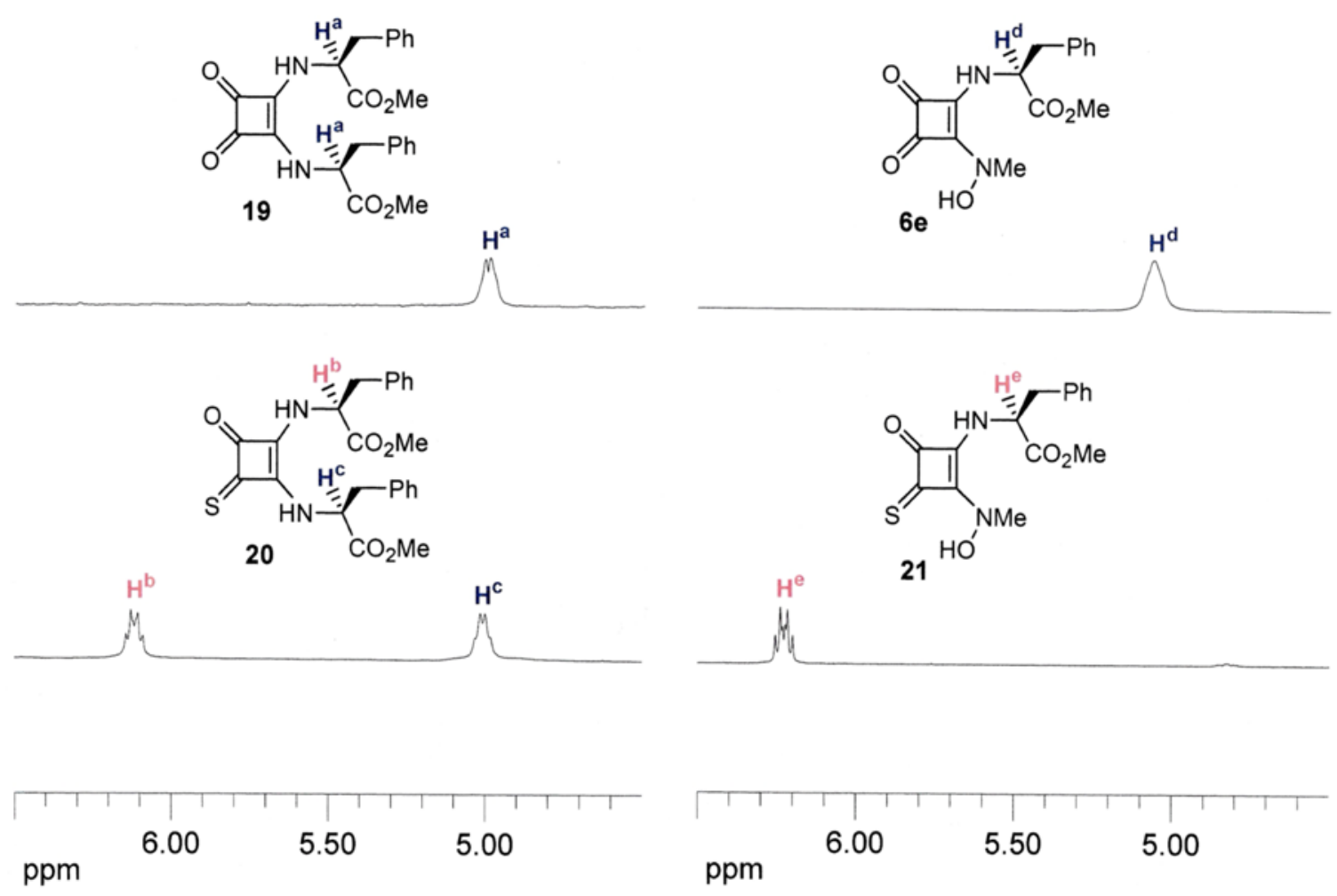

FIGURE 4.

Changes that occur in the ${ }^{1} \mathrm{H}$ NMR spectra of compounds $\mathbf{1 9}$ and $\mathbf{6 e}$ upon monothionation of the cyclobutenedione core. 


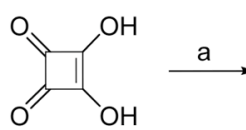

1

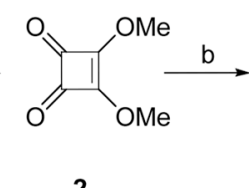

2

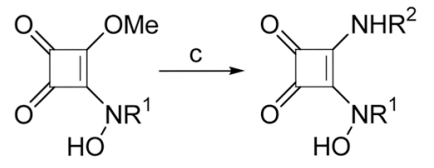

3a: $\mathrm{R}^{1}=\mathrm{H}$

3b: $R^{1}=M e$ 3c: $\mathrm{R}^{1}=$ cyclo 3d: $R^{1}=$ benzyl

3e: $R^{1}=$ isopropyl

4a: $\mathrm{R}^{1}=\mathrm{H}, \mathrm{R}^{2}=\mathrm{CH}_{2} \mathrm{CH}\left(\mathrm{CH}_{3}\right)_{2}$

4b: $\mathrm{R}^{1}=\mathrm{H}, \mathrm{R}^{2}=\left(\mathrm{CH}_{2}\right)_{5} \mathrm{CH}_{3}$

4c: $\mathrm{R}^{1}=\mathrm{Me}, \mathrm{R}^{2}=\left(\mathrm{CH}_{2}\right)_{5} \mathrm{CH}_{3}$

4d: $\mathrm{R}^{1}=\mathrm{Me}, \mathrm{R}^{2}=\left(\mathrm{CH}_{2}\right)_{4} \mathrm{CH}_{3}$

4e: $\mathrm{R}^{1}=$ cyclohexyl, $\mathrm{R}^{2}=\left(\mathrm{CH}_{2}\right)_{5} \mathrm{CH}_{3}$

4f: $\mathrm{R}^{1}=$ benzyl, $\mathrm{R}^{2}=\left(\mathrm{CH}_{2}\right)_{5} \mathrm{CH}_{3}$

SCHEME 1a.

${ }^{a}$ Reagents: (a) $\mathrm{CH}\left(\mathrm{OCH}_{3}\right)_{3}, \mathrm{MeOH}, \Delta$; (b) $\mathrm{HONHR}^{1} \cdot \mathrm{HCl}, \mathrm{KOH}, \mathrm{MeOH}$; (c) $\mathrm{H}_{2} \mathrm{NR}^{2}$, $\mathrm{MeOH}$. 
<smiles>[R]Nc1c(OC)c(=O)c1=O</smiles>

$$
\begin{aligned}
& \text { 3b: } R^{1}=M e \\
& 3 e: R^{1}=\mathrm{CH}\left(\mathrm{CH}_{3}\right)_{2}
\end{aligned}
$$<smiles>[R3]C(N)C(=O)OC</smiles>
$\mathrm{R}^{3}=$ side chain of amino acid

5a: $R^{3}=11$ e $5 \mathbf{b}^{b}: \mathbf{R}^{3}=$ Nle 5c: $R^{3}=$ Leu 5d: $R^{3}=$ Phe

5e: $\mathrm{R}^{3}=\mathrm{Trp}$

5f : $R^{3}=$ Met

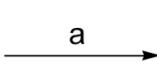<smiles>[R1]NC1=CCCC1=O</smiles>
$\mathrm{HO}$

$\mathrm{R}^{3}=$ side chain of amino acid 6a: $R^{1}=M e, R^{3}=\| l e$ 6b: $\mathrm{R}^{1}=\mathrm{CH}\left(\mathrm{CH}_{3}\right)_{2}, \mathrm{R}^{3}=\| l e$ $6 c^{b}: R^{1}=M e, R^{3}=$ Nle 6d: $R^{1}=M e, R^{3}=$ Leu 6e: $R^{1}=M e, R^{3}=$ Phe 6f: $R^{1}=M e, R^{3}=\operatorname{Trp}$ 6g: $R^{1}=M e, R^{3}=$ Met

SCHEME 2a.

${ }^{a}$ Reagents: (a) $\mathrm{MeOH}, \mathrm{KOH} .{ }^{b}$ Racemic Nle was used to prepare $\mathbf{5 b}$ and $\mathbf{6 c}$. 


$$
\begin{aligned}
& \text { (c) }
\end{aligned}
$$

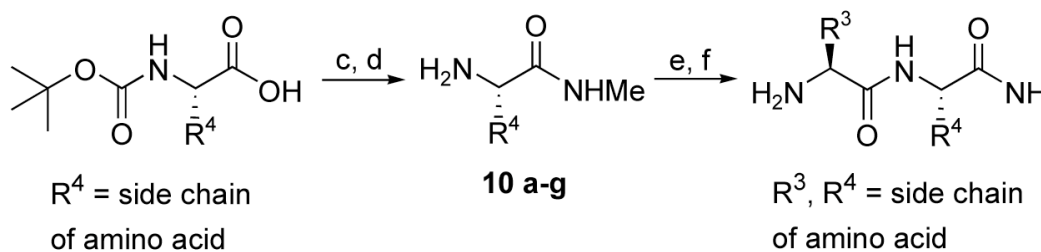

$$
\begin{aligned}
& \text { 9a: } R^{4}=\text { Tle } \\
& \text { 11a: } R^{3}=\text { lle, } R^{4}=\text { Tle } \\
& \text { 9b: } R^{4}=\text { Chg } \\
& \text { 9c: } R^{4}=\operatorname{Tyr}(\mathrm{Me}) \\
& \text { 9d: } R^{4}=\text { Phe } \\
& \text { 9e: } R^{4}=P h g \\
& \text { 9f: } R^{4}=\operatorname{Trp} \\
& \text { 9g: } R^{4}=\text { Leu } \\
& \text { 11b: } R^{3}=\| l e, R^{4}=C h g \\
& \text { 11c: } R^{3}=\| l e, R^{4}=\operatorname{Tyr}(\mathrm{Me}) \\
& \text { 11d: } R^{3}=\text { lle, } R^{4}=\text { Phe } \\
& \text { 11e: } R^{3}=\text { lle, } R^{4}=\text { Phg } \\
& \text { 11f: } R^{3}=\text { Ile, } R^{4}=\operatorname{Trp} \\
& \text { 11g: } R^{3}=\text { lle, } R^{4}=\text { Leu } \\
& \text { 11h: } R^{3}=\text { Leu, } R^{4}=\text { Tle }
\end{aligned}
$$

SCHEME 3a.

${ }^{a}$ Reagents: (a) $(\mathrm{BuO})_{3} \mathrm{CH}, \mathrm{BuOH}$, reflux; (b) $\mathrm{HONHMe} \cdot \mathrm{HCl}, \mathrm{KOH}, \mathrm{MeOH}$; (c) $\mathrm{NH}_{2} \mathrm{Me}, N$ hydroxysuccinimide (NHS), 1-ethyl-3-(3-dimethylaminopropyl)-carbodiimide hydrochloride (EDC), DMF; (d) $50 \%$ TFA, $\mathrm{CH}_{2} \mathrm{Cl}_{2}$; (e) NHS, $N$-Boc-Ile or $N$-Boc-Leu, EDC, DMF; (f) $50 \%$ TFA, $\mathrm{CH}_{2} \mathrm{Cl}_{2} ;(\mathrm{g}) \mathrm{MeOH}$. Tle = tert-leucine, $\mathrm{Chg}=$ cyclohexylglycine, $\mathrm{Phg}=$ phenylglycine . ${ }^{b}$ See Table 3 for specific structures. 


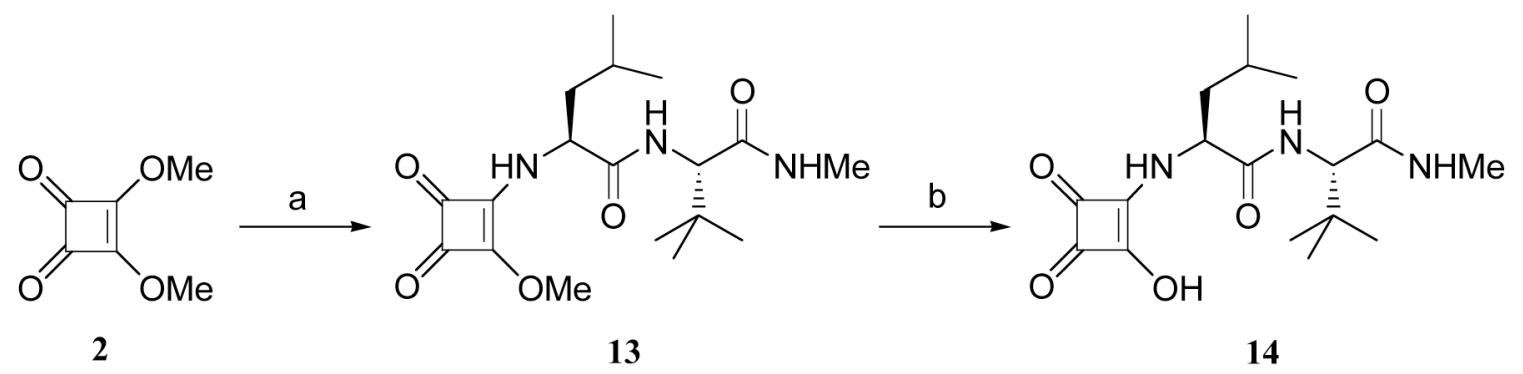

SCHEME 4a.

${ }^{a}$ Reagents: (a) H-Leu-Tle-NHMe, MeOH, reflux; (b) $0.15 \mathrm{~N} \mathrm{HCl}, \mathrm{MeOH}$, reflux. 


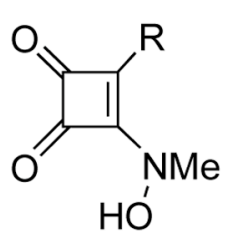

6a: $\mathrm{R}=\mathrm{HN}-\mathrm{Ile}-\mathrm{OMe}$

12d: $\mathrm{R}=\mathrm{HN}-$ lle-Phe-NHMe

12g: $\mathrm{R}=\mathrm{HN}-$ Ile-Leu-NHMe

12h: $\mathrm{R}=\mathrm{HN}-$ Leu-Tle-NHMe
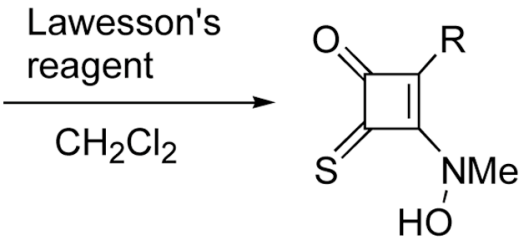

15: $\mathrm{R}=\mathrm{HN}-\mathrm{lle}-\mathrm{OMe}$

16: $\mathrm{R}=\mathrm{HN}-$ lle-Phe-NHMe

17: $\mathrm{R}=\mathrm{HN}$-lle-Leu-NHMe

18: $\mathrm{R}=\mathrm{HN}-\mathrm{Leu}-\mathrm{Tle}-\mathrm{NHMe}$

SCHEME 5.

Thionation of Cyclobutenediones 

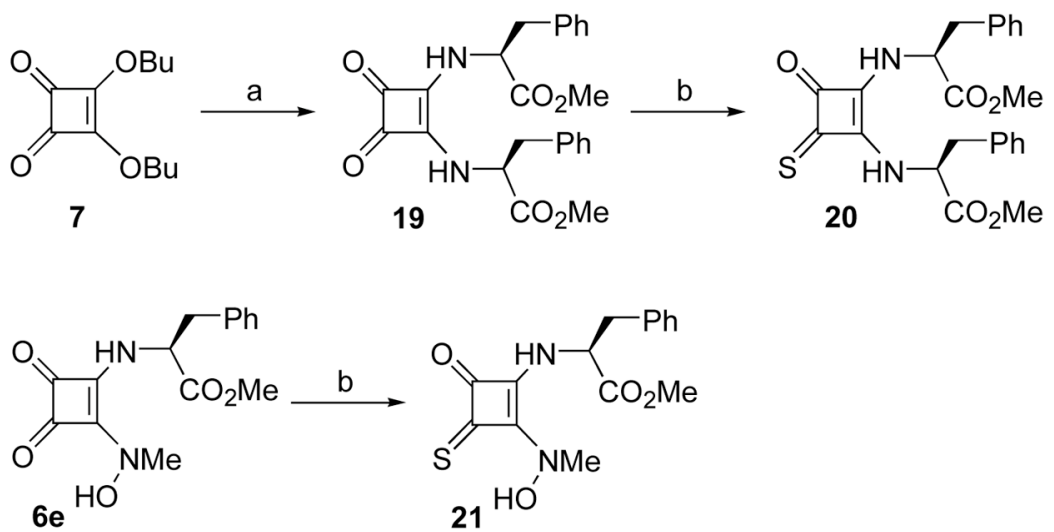

SCHEME 6a.

${ }^{a}$ Reagents: (a) L-Phe-OMe· $\mathrm{HCl}, \mathrm{KOH}, \mathrm{MeOH}$; (b) Lawesson's reagent, $\mathrm{CH}_{2} \mathrm{Cl}_{2}, 25^{\circ} \mathrm{C}$. 
TABLE 1

Inhibition of MMP-1 by Compounds $4 \mathrm{a}-\mathrm{f}$

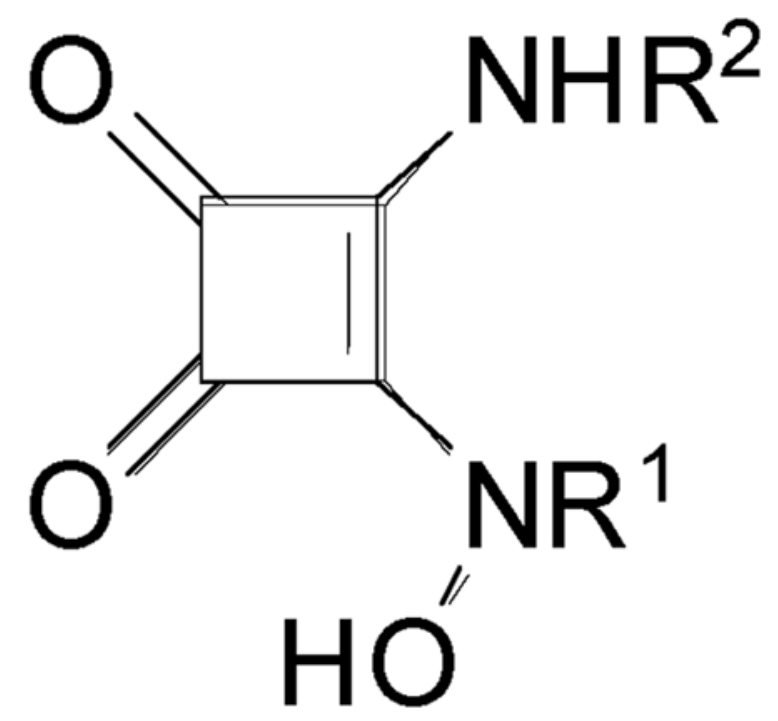

\begin{tabular}{|c|c|c|c|}
\hline compound & $\mathbf{R}^{1}$ & $\mathbf{R}^{2}$ & $\mathrm{IC}_{50}(\mathrm{mM})^{a}$ \\
\hline $4 a$ & $\mathrm{H}$ & $-\mathrm{CH}_{2} \mathrm{CH}\left(\mathrm{CH}_{3}\right)_{2}$ & $1.8 \pm 0.3$ \\
\hline $4 \mathrm{~b}$ & $\mathrm{H}$ & $-\left(\mathrm{CH}_{2}\right)_{5} \mathrm{CH}_{3}$ & $1.0 \pm 0.2$ \\
\hline $4 \mathrm{c}$ & Me & $-\left(\mathrm{CH}_{2}\right)_{5} \mathrm{CH}_{3}$ & $0.31 \pm 0.03$ \\
\hline $4 d$ & $\mathrm{Me}$ & $-\left(\mathrm{CH}_{2}\right)_{4} \mathrm{CH}_{3}$ & $0.31 \pm 0.03$ \\
\hline $4 e$ & cyclohexyl & $-\left(\mathrm{CH}_{2}\right)_{5} \mathrm{CH}_{3}$ & $>10$ \\
\hline $4 f$ & benzyl & $-\left(\mathrm{CH}_{2}\right)_{5} \mathrm{CH}_{3}$ & $>10$ \\
\hline
\end{tabular}

${ }^{a}$ All experiments were performed in duplicate. 
TABLE 2

Inhibition of MMP-1 by Compounds 6a-g

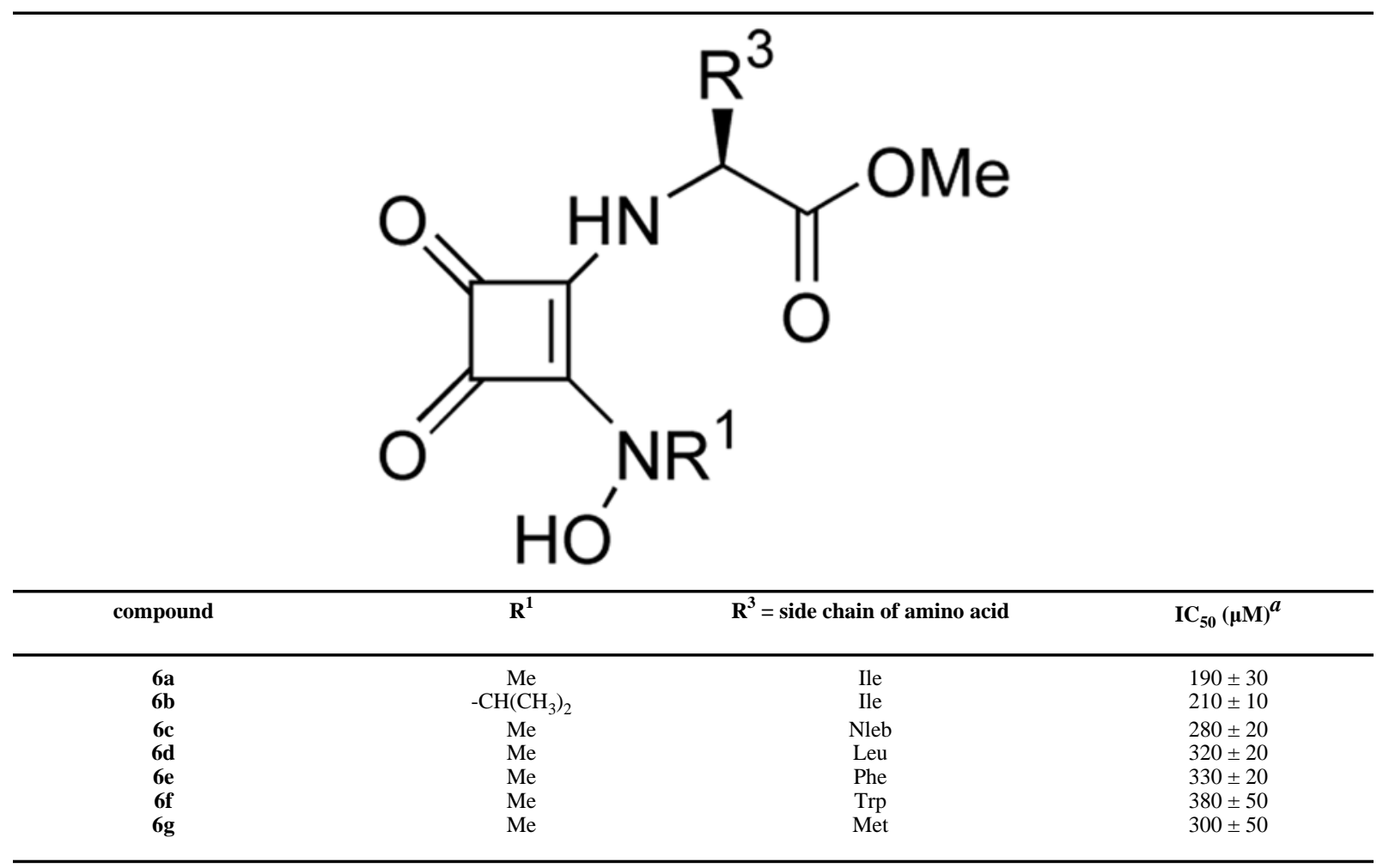

${ }^{a}$ All experiments were performed in duplicate.

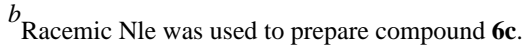


TABLE 3

Inhibition of MMP-1 by Dipeptides $12 \mathrm{a}-\mathrm{h}^{a}$

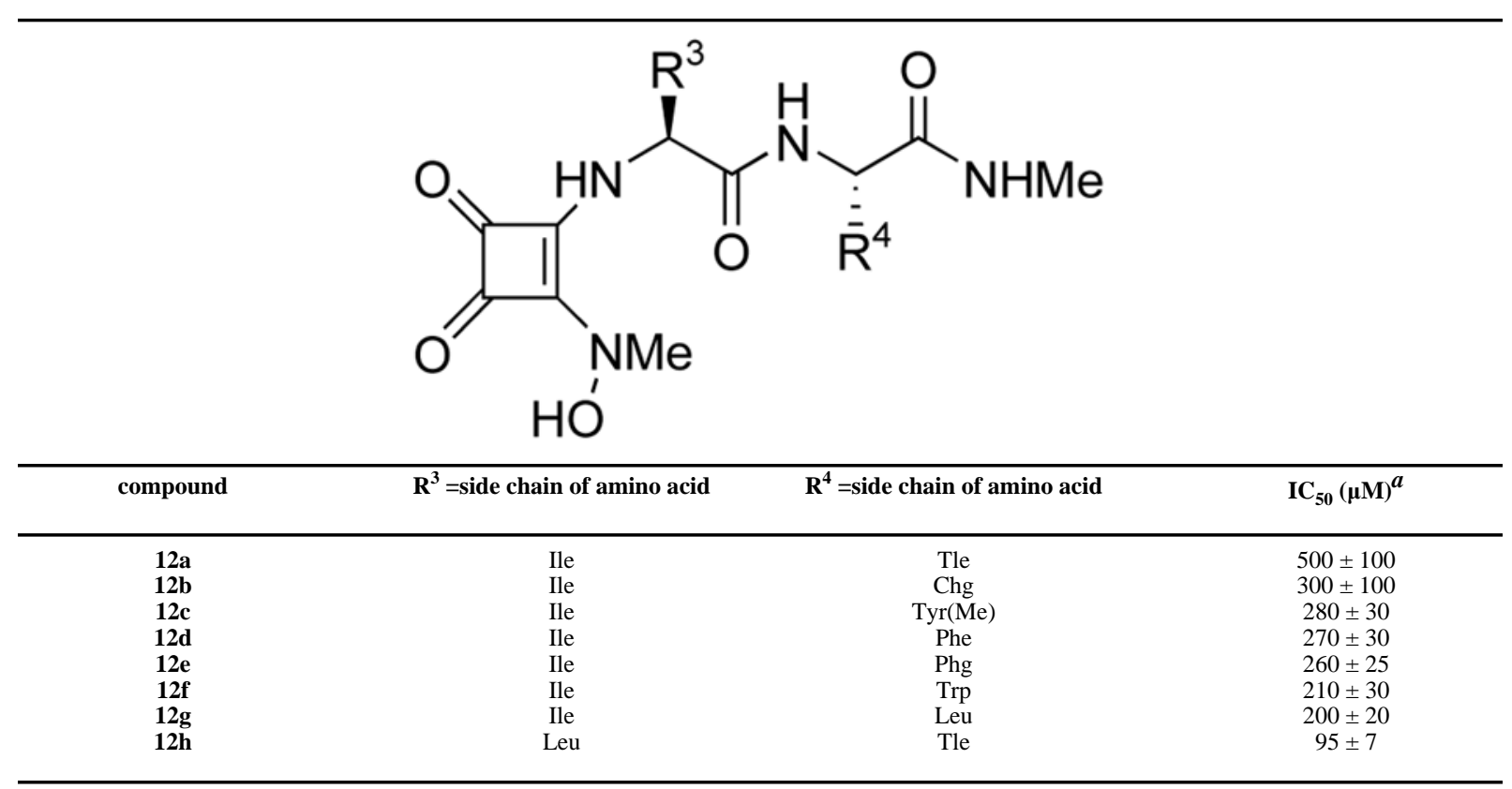

${ }^{a}$ All experiments performed in duplicate. 
TABLE 4

Inhibition of MMP-1 by Thiocarbonyl-Containing Inhibitors

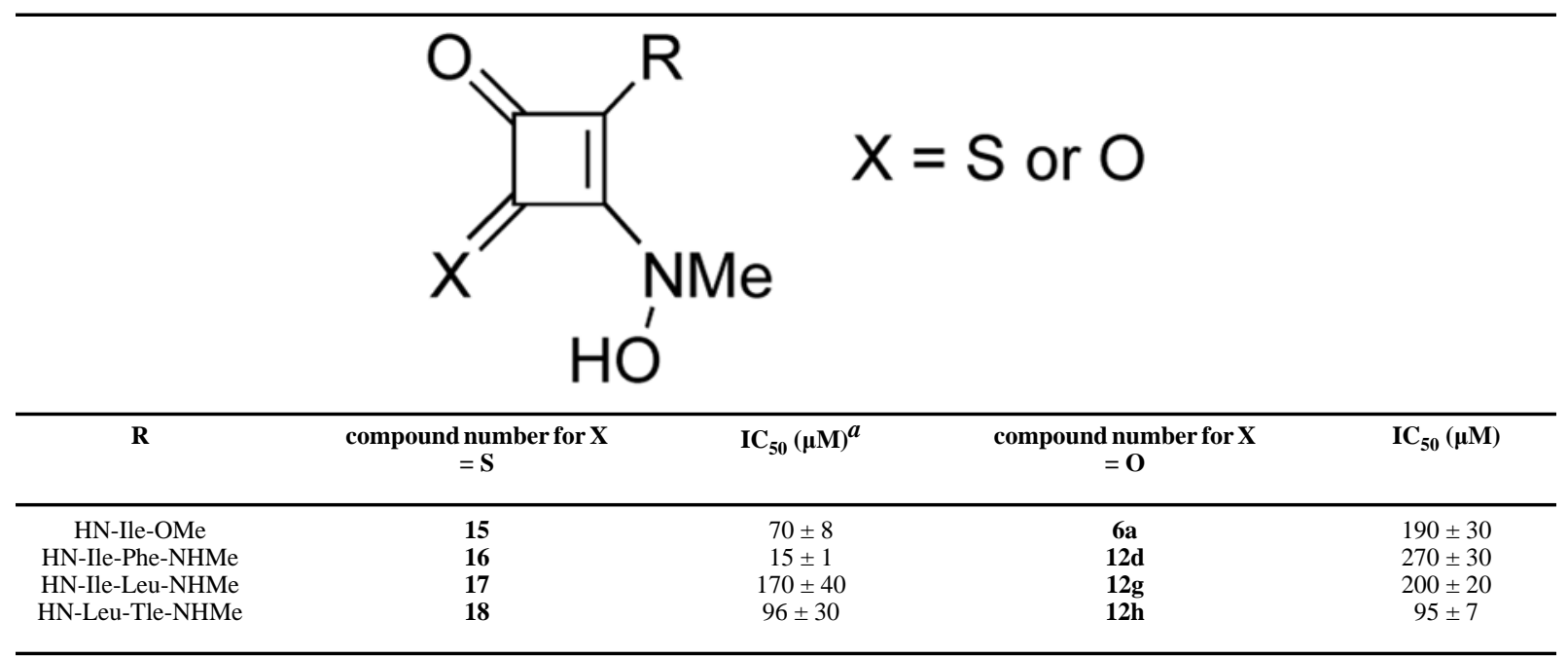

${ }^{a}$ All experiments performed in duplicate. 